OPEN ACCESS

Edited by:

Mustafa Culha

Oregon Health and Science University,

United States

Reviewed by:

Ali Zarrabi,

Sabanci University, Turkey

S. Sibel Erdem,

Istanbul Medipol University, Turkey

*Correspondence:

Hafiz M. N. labal

hafiz.iqbal@tec.mx

Specialty section:

This article was submitted to

Nanobiotechnology,

a section of the journal Frontiers in Bioengineering and

Biotechnology

Received: 02 July 2020 Accepted: 24 November 2020 Published: 15 December 2020

Citation:

Aguilar-Pérez KM, Avilés-Castrillo Jl,

Medina DI, Parra-Saldivar $R$ and

labal HMN (2020) Insight Into

Nanoliposomes as Smart Nanocarriers for Greening the Twenty-First Century

Biomedical Settings.

Front. Bioeng. Biotechnol. 8:579536.

doi: 10.3389/fbioe.2020.579536

\section{Insight Into Nanoliposomes as Smart Nanocarriers for Greening the Twenty-First Century Biomedical Settings}

\author{
K. M. Aguilar-Pérez, J. I. Avilés-Castrillo, Dora I. Medina, Roberto Parra-Saldivar and \\ Hafiz M. N. Iqbal*
}

Tecnologico de Monterrey, School of Engineering and Sciences, Monterrey, Mexico

The necessity to develop more efficient, biocompatible, patient compliance, and safer treatments in biomedical settings is receiving special attention using nanotechnology as a potential platform to design new drug delivery systems (DDS). Despite the broad range of nanocarrier systems in drug delivery, lack of biocompatibility, poor penetration, low entrapment efficiency, and toxicity are significant challenges that remain to address. Such practices are even more demanding when bioactive agents are intended to be loaded on a nanocarrier system, especially for topical treatment purposes. For the aforesaid reasons, the search for more efficient nano-vesicular systems, such as nanoliposomes, with a high biocompatibility index and controlled releases has increased considerably in the past few decades. Owing to the stratum corneum layer barrier of the skin, the in-practice conventional/conformist drug delivery methods are inefficient, and the effect of the administered therapeutic cues is limited. The current advancement at the nanoscale has transformed the drug delivery sector. Nanoliposomes, as robust nanocarriers, are becoming popular for biomedical applications because of safety, patient compliance, and quick action. Herein, we reviewed state-of-the-art nanoliposomes as a smart and sophisticated drug delivery approach. Following a brief introduction, the drug delivery mechanism of nanoliposomes is discussed with suitable examples for the treatment of numerous diseases with a brief emphasis on fungal infections. The latter half of the work is focused on the applied perspective and clinical translation of nanoliposomes. Furthermore, a detailed overview of clinical applications and future perspectives has been included in this review.

Keywords: nanoliposomes, nanocarriers, fabrication strategies, influencing factors, drug-loaded constructs, antifungal, targeted drug delivery, biomedical applications

\section{INTRODUCTION－PROBLEM STATEMENT AND OPPORTUNITIES}

Conventional drug delivery systems (DDS) are used to deliver therapeutic molecules into the human body either by oral consumption, injection, or topical administration. These systems were extensively in practice and accepted as convenient in terms of ease in administration. However, disadvantages are governed mainly because of the lack of compatibility at requisite level, poor biodistribution, burst or disrupted release, and low accuracy to reach the target sites in a sustainable 
and sophisticated manner (Dang and Guan, 2020). There is a dire need for highly effective and less/non-toxic alternatives to treat existing and emerging diseases. Besides, this has also provoked the medical sector authorities to search for robust therapeutic agents and new ways to increase the efficacy of traditional drug delivery agents (Taboada and Grooters, 2008). Scientists have engineered several types of nanocarrier mechanisms, such as solid lipid nanoparticles (SLN), liposomes, polymeric micelles, metallic nanoparticles (MNPs), spanlastics, nanoemulsions, nanoliposomes, among others (Taboada and Grooters, 2008; Elsherif et al., 2017; Huang et al., 2017; Zamani et al., 2018; Permana et al., 2019; Yang et al., 2020), either to develop new drug formulations or improve the existing ones. Many of these nano-systems are capable of inducing/imparting pharmacological activities, enhance drug dynamism, and improve physical stability to attain controlled release characteristics (Haury et al., 2017). Furthermore, the newer nanomedicines with a topical approach can counteract the issues associated with conventional and systemic therapy for the treatment of infections and, at the same time, reducing the highcost impact and minimizing long-term side effects (Gupta et al., 2017).

Nanoliposomes have been referred to as nanoscale bilayer lipid vesicles since the term liposome is a broad definition, including various types of vesicles with average size up to several micrometers (Mozafari and Mortazavi, 2005; Patil and Jadhav, 2014). Nanoliposomes present a greater surface area and have acceptable stability profile to preserve their size within nanometric scales, e.g., as small as $20-100 \mathrm{~nm}$ (small liposomes) and >100 nm (large liposomes) (Khorasani et al., 2018). These carriers are mainly composed of lipids and phospholipids. However, some contain other molecules, such as carbohydrates, antioxidants, proteins, or sterols in their structure (Mozafari and Khosravi-Darani, 2007). Due to their amphiphilic nature, they have the potential to entrap and release a massive range of hydrophilic and hydrophobic compounds simultaneously providing a combined benefit. Additionally, their characteristic bilayer structure is highly compatible with the skin surface, allowing them to act as penetration enhancers of bioactive compounds toward targeted sites (Farghaly et al., 2017). Compared with other nano DDS, nanoliposomes have the advantage of being produced using natural and inexpensive ingredients on an industrial scale (Demirci et al., 2017). This advantage, together with biocompatibility and biodegradability, make nanoliposomes very fascinating as "smart" drug delivery vehicles. Comparative overview of advantages and disadvantages of liposomes and nanoliposomes are summarized in Table 1. Keeping in mind the given attributes of liposome and nanoliposomes in Table 1, continuous research to enhance the already known properties of nanoliposomes keeps constant among research groups by conferring new structural characteristics throughout possible mechanisms of synthesis and surface modification to improve their potentialities, stability, and shelf-life (Jin et al., 2018). The present review focuses on the recent development in nanoliposome-based DDS with a brief emphasis on fungal infections. We also summarized fabrication techniques and several influencing factors that can
TABLE 1 | Comparative overview of advantages and disadvantages of liposomes and nanoliposomes.

\begin{tabular}{|c|c|}
\hline Advantages & Disadvantages \\
\hline \multicolumn{2}{|l|}{ LIPOSOMES } \\
\hline $\begin{array}{l}\checkmark \text { Entrapment of hydrophilic and } \\
\text { hydrophobic compounds } \\
\text { separated or simultaneously. }\end{array}$ & $\begin{array}{l}x \text { Reduction in encapsulation } \\
\text { efficiency due to size enlargement }\end{array}$ \\
\hline $\begin{array}{l}\checkmark \text { The increase in number of layers } \\
\text { (e.g., kinetic constraints) may be } \\
\text { beneficial to prevents or delays the } \\
\text { release of active molecules. }\end{array}$ & $\begin{array}{l}x \text { Higher physical instability during } \\
\text { storage. }\end{array}$ \\
\hline$\checkmark$ Made of natural ingredients & $\begin{array}{l}x \text { Susceptibility to fast clearance from } \\
\text { the bloodstream }\end{array}$ \\
\hline$\checkmark$ Simple fabrication process & $x$ Drug leakage \\
\hline $\begin{array}{l}\checkmark \text { Possibility of surface } \\
\text { functionalization }\end{array}$ & $\begin{array}{l}x \text { Higher susceptibility to be capture } \\
\text { by RES }\end{array}$ \\
\hline$\checkmark$ Cost-effectiveness & $\begin{array}{l}\text { x Reduced bioavailability compared } \\
\text { to nanoliposomes }\end{array}$ \\
\hline \multicolumn{2}{|l|}{ NANOLIPOSOMES } \\
\hline $\begin{array}{l}\checkmark \text { Entrapment of hydrophilic and } \\
\text { hydrophobic compounds } \\
\text { separated or simultaneously. }\end{array}$ & $\begin{array}{l}x \text { Manufacturing process usually } \\
\text { involves mechanical energy (e.g., } \\
\text { sonication, homogenization, } \\
\text { microfluidization, etc.) that may } \\
\text { degrade the lipid structure. }\end{array}$ \\
\hline$\checkmark$ Reduced toxicity and side-effects & $\begin{array}{l}x \text { Aggregation and coalescence can } \\
\text { occur due to stronger electrostatic } \\
\text { interactions. }\end{array}$ \\
\hline $\begin{array}{l}\checkmark \text { Greater stability when incorporated } \\
\text { into real products }\end{array}$ & $\begin{array}{l}x \text { More clinical trials are still } \\
\text { necessary }\end{array}$ \\
\hline $\begin{array}{l}\checkmark \text { Higher surface area-to-volume } \\
\text { ratio }\end{array}$ & $\begin{array}{l}x \text { In some cases, the use of } \\
\text { surfactants as stabilizers is needed. }\end{array}$ \\
\hline $\begin{array}{l}\checkmark \text { Better solubility and accurate } \\
\text { targeting }\end{array}$ & $x$ Reduced drug storage capacities \\
\hline $\begin{array}{l}\checkmark \text { Delayed body clearance and better } \\
\text { suitability for chemotherapeutics } \\
\text { delivery }\end{array}$ & $\begin{array}{l}x \text { The in vivo fate is still not fully } \\
\text { understood }\end{array}$ \\
\hline
\end{tabular}

significantly affect the overall fabrication and performance of nanoliposome-based DDS. Given, the current state of the art, including advantages and limitations, and a general overview of other novel nanostructured carriers that also exhibit important features for biomedical applications are discussed with suitable examples.

\section{NANOSTRUCTURED SYSTEMS-A DRIVE TOWARD OPTIMUM PERFORMANCE}

Nanostructured DDS can upgrade the features of traditional drug administration within the biomedical field. The use of nano lipid carriers is considered a safe route of drug administration (Haury et al., 2017; de Matos et al., 2019). Notwithstanding the considerable variety of nanostructured systems that have been used for biomedical purposes, there are still several challenges to overcome. For instance, some studies have reported the toxicity behavior of MNPs in the central nervous system (Sawicki et al., 2019). In contrast, bio-ceramic nanoparticles have 
been successfully applied for prosthesis, implants, and tissue regeneration (Thian et al., 2017). Nevertheless, their rate of clearance from the body by bloodstream varies from material to material and leads to their accumulation in body organs or mononuclear phagocytic system (Singh et al., 2017). Couple with this, the side effects and data related to toxicity effects may vary when the administration route, fabrication process, and functionalization agents are considered. Nanoliposomes have been investigated and incorporated into medicines for different purposes. The Food and Drug Administration (FDA) had approved their use in cancer therapy, vaccine delivery, fungal and microbial infections, analgesics, among others resulting in their high biocompatibility with the human body and potential pharmacokinetic profile (Inglut et al., 2020). Therefore, they can enhance the pharmacokinetic and pharmacodynamic profiles of the therapeutic payload, facilitate controlled and sustained release of the loaded drugs (Mohammadabadi and Mozafari, 2018).

\section{Nanoliposomes}

Broadly speaking, the nanoliposomes are defined as bilayer lipid vesicles, as shown in Figure 1, which possess and maintain nanometric size ranges during storage and applications (Khorasani et al., 2018). Due to their bilayer structure, composed of lipidic and aqueous sections, these nano-systems can encapsulate hydrophilic and hydrophobic compounds individually or at the same time. Notwithstanding the potentialities of these nano-systems as drug delivery carriers, low physical stability, high sensitivity to temperature, and $\mathrm{pH}$ variations are significant challenges to overcome when commercial use is intended. However, numerous investigations have been reported the surface modification to improve stability and storage (Milani et al., 2019). In consequence of enhanced stability and targeting, the amount of entrapped material is less than the amount required without encapsulation. This may be helpful when working with high-cost bioactive compounds. Additionally, the use of natural and inexpensive ingredients (e.g., soy, egg yolk, sunflower, milk) for nanoliposome preparation is possible, thus, optimizing the cost-effectiveness of the final product (Khosravi-Darani and Mozafari, 2010). Because of these unique properties, numerous clinical trials have revealed that nanoliposomes are great candidates for varied delivery systems, such as anti-cancer, anti-fungal, and anti-biotic drugs, the delivery of gene medicines, and the delivery of anesthetics and anti-inflammatory drugs (Allen and Cullis, 2013). Advantages of nanoliposomes based formulations with respect to non-nanoliposomes based formulations for oral, topical, and intramuscular drug administration are presented in Figure 2.

Nanoliposomes have also been combined with other clinical techniques to improve their mechanism of action. Gelfuso et al. (2020) tested the effectiveness of voriconazole based nanoliposomes along with iontophoresis for the treatment of fungal keratitis. The system was evaluated against Candida glabrata culture, the minimal inhibitory concentration (MIC) for voriconazole in the presence/absence of iontophoresis on C. glabrata was $0.14 \pm 0$ and $0.28 \pm 0 \mu \mathrm{g} / \mathrm{ml}$. The liposomal formulations did not present an excellent advantage for iontophoretic delivery at a current density of $2 \mathrm{~mA} / \mathrm{cm}^{2}$. Besides, the morphological analyses performed by Transmission Electronic Microscopy (TEM) displayed an oval shape close to $100 \mathrm{~nm}$. These results confirmed the excellent stability and the strong capability of nanoliposomes for voriconazole passive delivery over commercial voriconazole medicine. Both carriers have been successfully applied for biomedical proposes in view of their drug delivery mechanism and release behavior (Khorasani et al., 2018; Subramani and Ganapathyswamy, 2020). Figure 3 represents the multi-functional characteristics of drug loading into nanoliposomes as a competent model for biomedical applications.

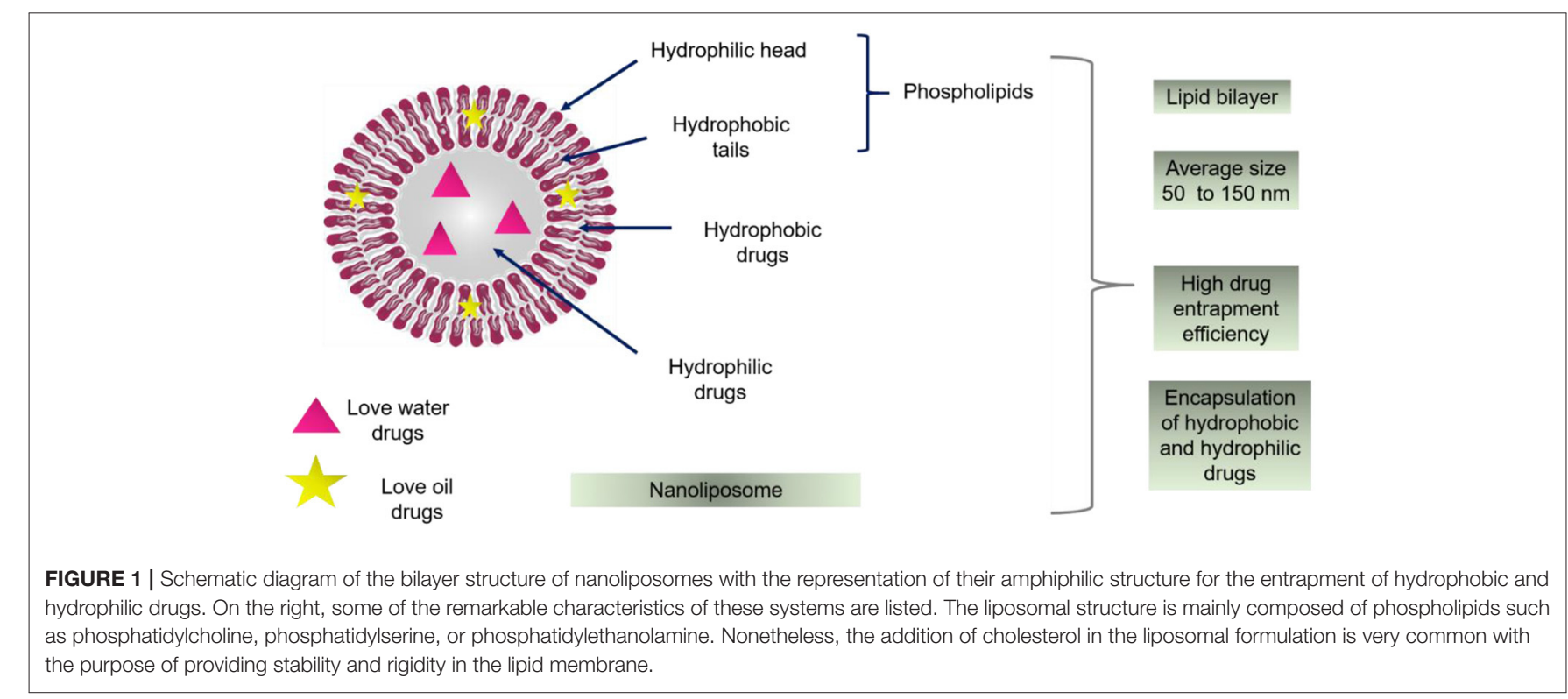




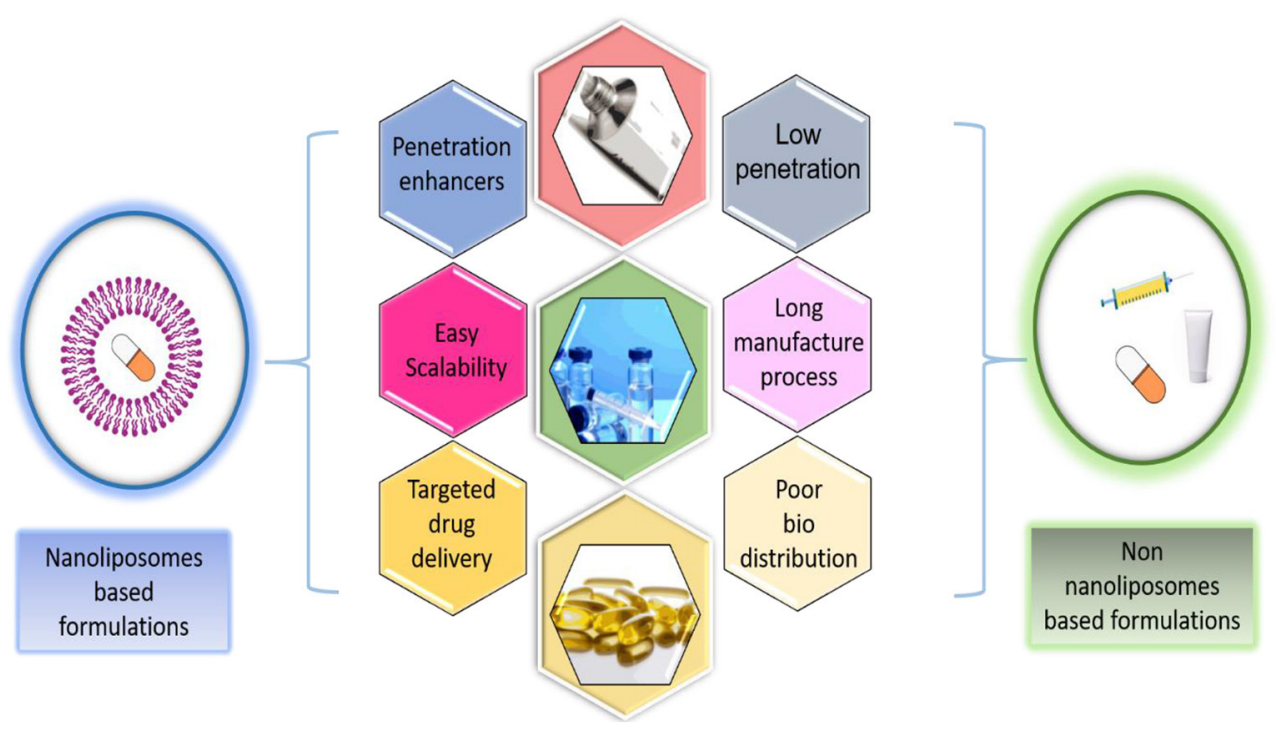

FIGURE 2 | Advantages of nanoliposomes based formulations respect to non-nanoliposomes based formulations for oral, topical, and intramuscular drug administration.

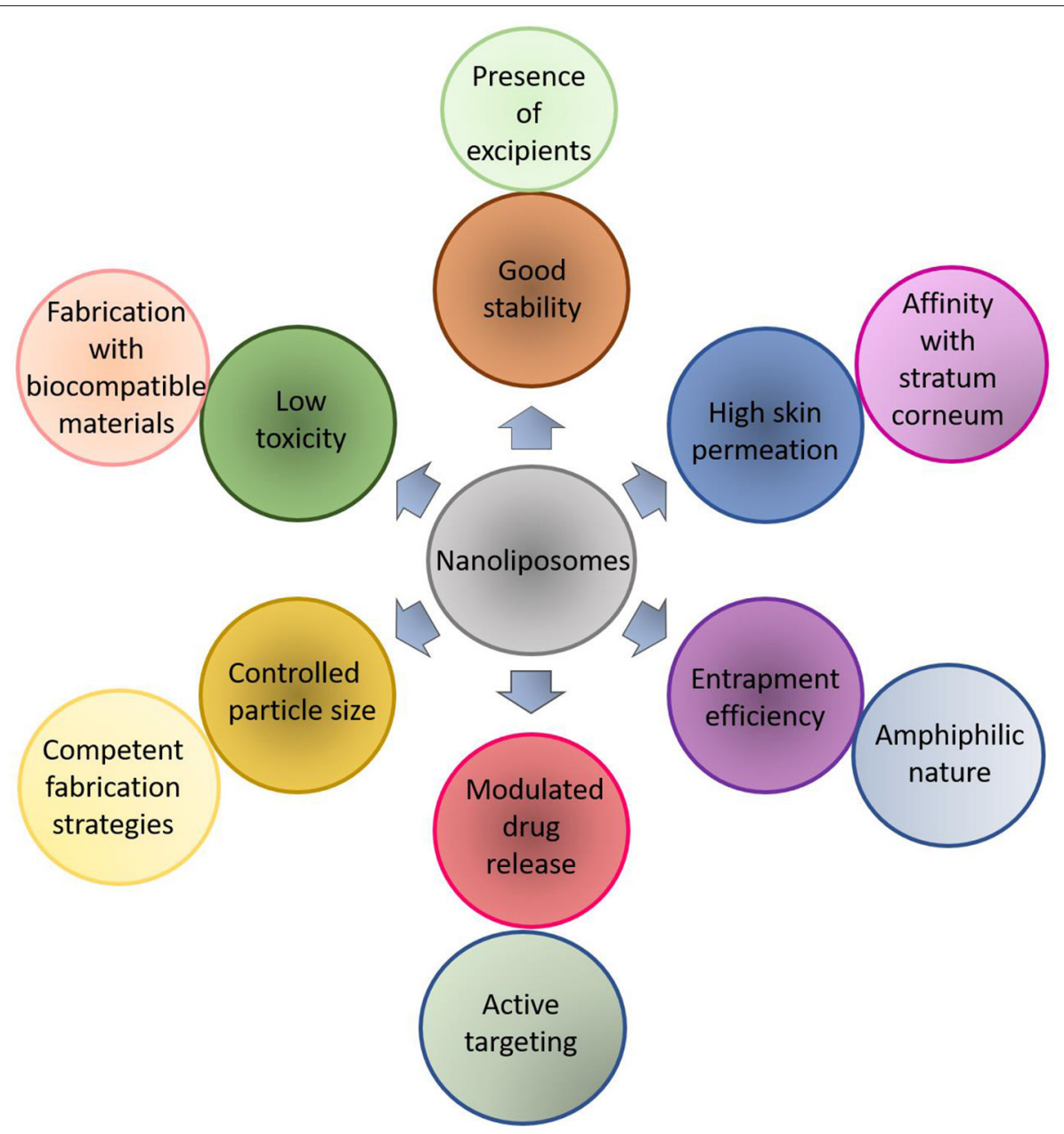

FIGURE 3 | Schematic representation of multi-functional characteristics of drug loading into nanoliposomes as a competent model for biomedical applications. 


\section{FABRICATION STRATEGIES-PROCESSING AND WORKFLOW}

\section{Thin-Film Hydratio-Sonication Method}

This methodology, also known as Bangham method (Bangham et al., 1965), is the most implemented to synthesize conventional nanoliposomes. A mixture of phospholipids is dissolved in a polar solvent (e.g., ethanol) with the hydrophobic drugs. Afterward, the solvent is evaporated (either via rotary evaporator or sample concentrator) above the transition temperature of phospholipid. Then, a film is formed at the bottom of the flask and kept drying under a vacuum desiccator for $24 \mathrm{~h}$ or more to remove traces of organic solvents before hydration. The hydration is carried out under stirring in the presence of distilled water or buffer solution such as phosphate buffer saline (PBS) or 4-(2-hydroxyethyl)-1-piperazineethanesulfonic acid (HEPES) (Gallez et al., 2020). Subsequently, the mixture is sonicated either through a bath or probe sonicator to reduce the vesicle size and to homogenize the sample.

\section{Ethanol Injection Technique}

This technique was described by Batzri and Korn (1973). An ethanol solution of phospholipids is injected under controlled conditions considering pump flow rate, stirring intensity, and injection temperature (above lipid transition temperature) into an aqueous phase. Subsequently, the solution remains under mechanical stirring on a magnetic stirrer or by rotary evaporation at room temperature under reduced pressure to remove the traces of solvent (Toniazzo et al., 2017; Hammoud et al., 2020).

\section{Reverse Phase Evaporation Method}

In this method, the lipid mixtures are dissolved in an organic solvent and solubilized with the aid of an ultrasonic bath. Then, a liquid solution, either water or buffer with stabilizers, is added to the mixture. Following that, the solvent is evaporated under reduced pressure by a rotary evaporator to promote a dense gel formation. An excess of the liquid solution is added to evaporate remains of organic solvent. The final formulation is submitted to dialysis, sonication, or centrifugation to homogenize the particle size. Nitrogen atmospheres can be implemented to purge the system to protect the lipid mixtures from degradation (Shi and Qi, 2018; da Rosa et al., 2019).

\section{Supercritical Fluid Technology}

A supercritical fluid is defined as a compound at temperature and pressure above their critical point exhibits properties of liquids such as density and gases such as compressibility. $\mathrm{CO}_{2}$ is the most regularly used supercritical fluid mainly due to its low price and other characteristics, including low critical temperature and pressure $\left(31.1^{\circ} \mathrm{C}\right.$ and $\left.73.6 \mathrm{bar}\right)$ and recyclability (Moreno et al., 2019). Supercritical fluid technology has been developed to reduce the use of organic solvents such as chloroform, ether, or methanol during the preparation of nanoliposomes due to their harmful risk to the environment and human health. Moreover, these substances result in challenging to separate by using conventional synthesis (Zhang et al., 2012). In Supercritical fluid technologies, the use of organic solvents is not always eluded. Still, whenever their use becomes necessary, they usually have a lower toxicity index than the previously mentioned solvents (Lesoin et al., 2011).

The most common supercritical fluid technologies that involve the fabrication of nanoliposomes are supercritical antisolvent (SAS) and rapid expansion of supercritical solutions (RESS). SAS implies the use of an organic liquid co-solvent which already contains the phospholipid mixture. It must be miscible in the presence of the supercritical fluid, which proceeds as an antisolvent to precipitate the lipid material, promoting nanoparticles' formation (Gupta and Xie, 2018; Schwartz et al., 2018). In the RESS procedure, solutes are dissolved at high pressure in the supercritical fluid, posteriorly the solution is decompressed with the aid of a nozzle and then precipitated by rapid expansion with the purpose to enable rapid nucleation. Subsequently, adequate particle formation, in this case, supercritical $\mathrm{CO}_{2}$ acts as a solvent (Debenedetti et al., 1993; Gomes et al., 2018).

\section{Supercritical Assisted Liposome Formation (SuperLip)}

This synthesis methodology belongs to the dense gas technologies. It consists in the use of a dense gas such as carbon dioxide $\left(\mathrm{CO}_{2}\right)$ to enhance the mixing between the organic phase (phospholipids and ethanol) and water and to remove the traces of ethanol from liposomes suspension. The organic mixture is pumped in a static mixer with $\mathrm{CO}_{2}$ under controlled pressure and temperature, usually $100 \mathrm{bar}$ and $40^{\circ} \mathrm{C}$ to obtain a gas-expanded solution. The resulting ethanol expanded solution is pumped with a water phase into a high-pressure chamber. Simultaneously, the water is sprayed throughout a nozzle. Finally, ethanol is separated from vesicles and water suspension and recovered in a separator by $\mathrm{CO}_{2}$ flushing out from the chamber under pressure at room temperature (Ciaglia et al., 2019; Trucillo et al., 2019). This technique's feasibility for the synthesis of nanoliposomes allows getting an adequate control of particle size and distribution and high entrapment efficiency (up to 84\%) (Trucillo et al., 2020).

\section{Depressurization of an Expanded Liquid Organic Solution (DELOS-SUSP)}

This technique is performed by adding a sample containing lipids and organic solvent into a vessel at working temperature $\left(\mathrm{T}_{\mathrm{w}}\right)$ and atmospheric pressure $\left(\mathrm{P}_{\mathrm{atm}}\right)$. The expansion of the lipid is carried out by adding a large amount of $\mathrm{CO}_{2}$ to obtain an expanded solution, considering that the lipids must be soluble in the $\mathrm{CO}_{2}$-expanded solvent to guarantee the formation of a single-phase inside the high-pressure chamber until reach the working pressure $\left(\mathrm{P}_{\mathrm{w}}\right)$. Finally, depressurization of $\mathrm{CO}_{2}$ - the expanded solution is done over a flow of aqueous phase from $\left(\mathrm{P}_{\mathrm{w}}\right)$ to $\left(\mathrm{P}_{\mathrm{atm}}\right)$ containing a surfactant whenever it is necessary to provide better uniformity to the vesicles (Elizondo et al., 2011). In this final step, a flow of $\mathrm{N}_{2}$ at $\mathrm{P}_{\mathrm{w}}$ is used to push down the $\mathrm{CO}_{2}$-expanded solution and to keep the pressure inside the vessel constant (Grimaldi et al., 2016). 


\section{Particles From Gas Saturated Solution (PGSS)}

This fabrication technique consists of two steps. The first step involves the saturation of a solute with $\mathrm{CO}_{2}$ in a mixing container at high pressures. The second step refers to the expansion of the gas saturated solution with the aid of a nozzle at $\left(\mathrm{P}_{\mathrm{atm}}\right)$. The formation of the material occurs during the development due to the fast reduction in temperature (JouleThompson effect), producing particle formation by solidifying the material. This technique has been used for the encapsulation of bioactive compounds in liposomes. However, entrapment efficiency reported is low compared to other techniques, such as the thin-film hydration method (Varona et al., 2011). Moreover, another study reported the development of high-quality vesicles, enough dispersion, and storage stability for up to 4 weeks (Zhao and Temelli, 2015).

\section{Depressurization of an Expanded Solution Into Aqueous Media (DESAM)}

In this technique, the hydration process is performed by depressurizing an expanded solution into an aqueous media via a nozzle. A mixture of lipids in an organic solvent is injected into an expansion chamber. The operating conditions are carried out at moderate temperatures and pressures below 60 bar. The expanded lipid solution is reached by pressurization through the addition of dense gas, and it is further heated into an aqueous media. The controlled release of the developed lipid solution is performed when the pressure is maintained by adding dense gas. The organic solvent is washed from the system. This ensures minimal residual solvent and can be separated and recycle with the gas leaving the system (Meure et al., 2009; Campardelli et al., 2015).

\section{Heating Method}

A new technique for the fast fabrication of nanoliposomes avoids using hazardous solvents developed by Mozafari et al. (2002) implies the use of a single vessel in the absence of solvents or detergents. The phospholipids and excipients are hydrated under an inert atmosphere for $1-2 \mathrm{~h}$ in an aqueous medium. Therefore, the ingredients are put through mechanical stirring after the addition of a polyol, such as glycerol, which acts as a cosolvent or dispersant at a temperature up to $120^{\circ} \mathrm{C}$ for $30 \mathrm{~min}$ to ensure a proper ingredients distribution in the aqueous medium. Once the ingredients are uniformly dispersed, drug compounds can be added either at a high or lower temperature, depending on their heat sensitivity (Danaei et al., 2018b).

\section{Mozafari Method}

This method belongs to one of the modern techniques for the synthesis of nanoliposomes developed. Given most of the current processes for the fabrication of nanoliposomes that require either solvents, high shear mixers, or pressurization. To overcome these drawbacks, Colas et al. (2007) introduced an improved version of the heating method for the encapsulation of nisin called Mozafari method. The authors proposed that nanoliposomes' synthesis can be carried out in a home-made glass vessel designed by Mozafari. This type of glass-bottle was developed to enhance the methodology's efficiency since the multiple turbulences contained in a single vessel enable to function as seven vessels simultaneously. Thus, having seven as the total number of turbulences. This method allows the manufacturing of nanoliposomes in a single step without employing solvents, detergents, and the need for pre-hydration. The liposomal ingredients are added in a preheated mixture that contains the active compound that is pretended to encapsulate and a polyol. Then the mixture is heated while stirring under a nitrogen atmosphere. If it is intended to incorporate cholesterol into the formulation, this must be added in the aqueous phase while stirring at elevated temperatures under a nitrogen atmosphere before mixing the other phospholipid components. Finally, the nanoliposomes suspension is subjected under an inert atmosphere above the lipid transition temperature to allow sample annealing and stabilization, as mentioned in previous work (Mozafari, 2010). Table 2 summarizes the advantages and disadvantages of each nanoliposome fabrication technique. Additionally, recent reports that discuss the fabrication strategies

TABLE 2 | Advantages and disadvantages of various fabrication techniques used for the development of nanoliposomes.

\begin{tabular}{|c|c|c|}
\hline $\begin{array}{l}\text { Fabrication } \\
\text { technique }\end{array}$ & Advantages & Disadvantages \\
\hline $\begin{array}{l}\text { Thin film } \\
\text { hydration-sonication } \\
\text { method }\end{array}$ & $\begin{array}{l}\text { Economic } \\
\text { Easy to perform }\end{array}$ & $\begin{array}{l}\text { Use of organic solvents } \\
\text { Exposure to mechanical } \\
\text { stress }\end{array}$ \\
\hline Ethanol injection & $\begin{array}{l}\text { Simple procedure } \\
\text { Good stability profile }\end{array}$ & $\begin{array}{l}\text { Low encapsulation } \\
\text { efficiency } \\
\text { Time consuming }\end{array}$ \\
\hline $\begin{array}{l}\text { Reverse phase } \\
\text { evaporation }\end{array}$ & $\begin{array}{l}\text { Simple design } \\
\text { Decent percentage of } \\
\text { encapsulation efficiency }\end{array}$ & $\begin{array}{l}\text { Large amount of organic } \\
\text { solvent }\end{array}$ \\
\hline SAS & $\begin{array}{l}\text { Low organic solvent } \\
\text { consumption }\end{array}$ & $\begin{array}{l}\text { Use of sophisticate } \\
\text { machinery, expensive }\end{array}$ \\
\hline RESS & $\begin{array}{l}\text { Absence of liquid organic } \\
\text { solvents } \\
\text { Mild processing } \\
\text { temperatures }\end{array}$ & $\begin{array}{l}\text { Implementation of complex } \\
\text { apparatus } \\
\text { Requirement of high } \\
\text { pressures }\end{array}$ \\
\hline SuperLip & $\begin{array}{l}\text { Control of particle size } \\
\text { High encapsulation } \\
\text { efficiency }\end{array}$ & $\begin{array}{l}\text { Use of high pressures } \\
\text { Use of } \mathrm{CO}_{2}\end{array}$ \\
\hline DELOS-SUSP & $\begin{array}{l}\text { Easy scale up production } \\
\text { Uniform particle size }\end{array}$ & $\begin{array}{l}\text { Low entrapment efficiency } \\
\text { Use of solvent and } \\
\text { necessity to produce an } \\
\text { expanded solution }\end{array}$ \\
\hline PGSS & $\begin{array}{l}\text { High encapsulation } \\
\text { efficiency } \\
\text { Larger particle sizes }\end{array}$ & $\begin{array}{l}\text { Use of expensive } \\
\text { instrumentation } \\
\text { Low stability }\end{array}$ \\
\hline DESAM & $\begin{array}{l}\text { Fast and simple for bulk } \\
\text { nanoliposome formation } \\
\text { Alternative to current gas } \\
\text { dense technologies }\end{array}$ & $\begin{array}{l}\text { Use of organic solvent } \\
\text { Multi step procedure }\end{array}$ \\
\hline Heating method & $\begin{array}{l}\text { Avoid the use of toxic } \\
\text { solvents and detergents }\end{array}$ & $\begin{array}{l}\text { Use of inert atmospheres } \\
\text { (Ar or } \mathrm{N}_{2} \text { ) }\end{array}$ \\
\hline Mozafari method & $\begin{array}{l}\text { Easy to perform } \\
\text { Brief protocol for industrial } \\
\text { scalability }\end{array}$ & $\begin{array}{l}\text { Use of inert atmospheres } \\
\text { and polyols }\end{array}$ \\
\hline
\end{tabular}


to engineer nanoliposomes for drug delivery purposes are outlined in Table 3.

\section{INFLUENCING FACTORS THAT AFFECT THE NANOLIPOSOMES PERFORMANCE}

\section{Permeability/Penetration Capacity}

Nanoliposomes raise targeting of drug penetration of active ingredients through vesicle adsorption onto the skin surface by the interaction of lipids part of nanoliposomes with the stratum corneum. The lipid bilayer of nanoliposomes can fuse with other bilayers due to its resemblance to the biological membrane, which simplifies the penetration into the epidermal barrier and helps in the transport of the core therapeutic material compared to other nano DDS (Siepmann et al., 2012; Arshad et al., 2020). The passage of nanoliposomes through the horny layer is enhanced by the occlusive effect that increases their permeability (Hofland et al., 1995; Touti et al., 2020). The occlusive effect refers to an increase of hydration in the stratum corneum in the presence of water, affecting percutaneous adsorption by amending segregation between the surface chemical and the skin (Foldvari et al., 1990). This passage can be favored by the active principle's affinity for the horny layer and promotes the increased penetration of lipid-soluble. The topical-based drug formulation that contains fats and/or polymers oils may also generate occlusive effects, becoming suitable for pharmaceutical and cosmetic applications (Zhai and Maibach, 2002; Van Tran et al., 2019).

TABLE 3 | Recent reports about fabrication strategies of nanoliposomes applied to substances of interest in drug delivery.

\begin{tabular}{lll}
\hline Synthesis technique & Encapsulated agent & Objective \\
\hline $\begin{array}{l}\text { Thin-film } \\
\text { hydration-sonication }\end{array}$ & calothrixin B & $\begin{array}{l}\text { To test anticancer activity against lung } \\
\text { and breast cell lines A549 and MCF-7 }\end{array}$ \\
Ethanol injection & Black seed oil (Nigella sativa) & $\begin{array}{l}\text { To enhance oral bioavailability and } \\
\text { improve therapeutic activity in small } \\
\text { animal studies of analgesia }\end{array}$
\end{tabular}

Reverse phase evaporation

Supercritical fluid technology

Supercritical assisted Liposome formation

(SuperLip)

Depressurization of an

Expanded Liquid

Organic Solution

(DELOS)

Particles from gas saturated solution PGSS

Depressurization of an Expanded Solution into Aqueous Media (DESAM) Heating method Plasmid DNA

Mozafari method

Polyunsaturated fatty acids (PUFAs): docosahexaenoic acid (DHA) and eicosapentaenoic acid (EPA)
To carry an efficient amount of pomegranate extract to sperm via lecithin nanoliposome to protect sperm against lipid peroxidation

To load melatonin in nanoliposomes as a delivery system in order to increase its oral bioavailability

Encapsulation of an antimicrobial agent for intravenous application

To produce protein-nanoliposome for the treatment of Lysosomal storage disorders (LSD)

To investigate the effect of pressure, depressurization rate and temperature on the characteristics of the final formulation

To design and validate a new process for bulk liposome formation

To prepare anionic nanoliposomes without using any volatile organic solvent or detergent in order to test their morphology, stability and DNA incorporation efficiency

To investigate the oxidation of bulk DHA and EPA incorporated into liposomes during cold $\left(4^{\circ} \mathrm{C}\right)$ storage
Results

High entrapment efficiency, Control size distribution, increased stability

Improvement of analgesic activity and oral bioavailability. Sucrose and cholesterol exhibited to improve the encapsulation efficiency of black seed oil.

Protection of ram sperm during cryopreservation without adverse effects. Pomegranate formulation improved the quality of ram semen after thawing

Uniform size distribution.

Slow release feature in early digestive

stages and more thorough

characteristics in later stages of simulated digestion

Inhibition growth of E. coli bacteria

Encapsulation efficiency up to $84 \%$

Enhanced enzymatic activity and

intracellular penetration.

Entrapment efficiency of $40 \%$

Quality of the vesicles depends on the dispersion of the phospholipid molecules prior to their reorganization during the processing

Range size from 50 to $200 \mathrm{~nm}$ Polydispersity index below 0.29

Good reproducibility, long-term stability and potential nano liposome production in large quantities.

Enhancement of the oxidative stability of DHA and EPA in aqueous media when compared with bulk systems
References

Yingyuad et al., 2018

Rushmi et al., 2017

Mehdipour et al., 2017

Zhang et al., 2017

Trucillo et al., 2020

Cabrera et al., 2016

Zhao and Temelli, 2015

Meure et al., 2009

Mozafari et al., 2002 
Nanoliposomes systems have received particular attention for drug delivery applications due to their bilayer structure that affords the substantial capability to entrap hydrophobic and hydrophilic molecules acting as penetration enhancers. Size is an essential factor to bear in mind since smaller sizes lead to larger surface areas and subsequently to greater reactivity and control the drug's release kinetics (Samadi et al., 2020). According to Sakdiset et al. (2018), composition and design are essential factors to consider for developing efficient nanoliposome with high skin permeation and improved performance. The research group found that 1,2-di- palmitoyl-sn-glycero-3-phosphoglycerol, sodium salt (DPPG) can be a promising phospholipid candidate for nanoliposome formulations with high skin penetrationenhancing effects. They tested the mechanism of interaction of empty nanoliposomes and entrapped caffeine where DPPG phospholipid and nanoliposome vesicles had a combined effect of disrupting the stratum corneum lipid barrier to carry both in the formulation through the skin. Pseudo ceramide loaded nanoliposomes were synthesized, and their role in skin barrier functions was investigated by Kim et al. (2019). The nanoliposomes functionalized like skin constituents were prepared using pseudo ceramides, $\mathrm{PO} 3 \mathrm{C}, \mathrm{PO} 6 \mathrm{C}, \mathrm{PO} 9 \mathrm{C}$, and loaded with baicalein. The in vivo skin permeation results showed that the nanoliposome formulation carried baicalein well and effectively penetrated the skin. The use of pseudo ceramides not only passed the skin barrier but also effectively transmitted the weakly soluble drug, baicalein, which demonstrated the use of nanoliposomes, as functional carriers, that effectively transmit the poorly soluble drug baicalein to the skin.

\section{Drug Loading Capacity}

The entrapment efficiency (EE) and loading capacity (LC) are crucial parameters for promising applications of nanoliposomes due to the necessity of produce formulations with the desired payload with minimal drug loss (Drummond et al., 2010). Among the reasons for medical applications of nanoliposomes is the effectiveness to load acceptable quantities of drugs needed to achieve therapeutic efficacy. However, it must consider several factors that may affect the performance of nanoliposomes as drug-loaded carriers (Zucker et al., 2009), developed a model based on loaded conditions of liposomes and nanoliposomes drugs'. They found that the most critical condition that affects loading capacity is the initial drug/lipid mole ratio. Precisely, when it is too high with values above 0.95 , low loading capacity is displayed due to excess drug that exceeds the liposomal loading capacity, which entails overloading damages in the lipid membrane leading to a lower final drug/lipid mole ratio. Moreover, some other factors, such as solubility, $\mathrm{pH}$, drug properties, temperature, and loading conditions, must be reviewed for suitable drug-loaded liposome formulations and to improve their development for clinical applications.

\section{Surface Modification}

A drug molecule's therapeutic potential depends on its availability at the target site at the requisite amount and for the required duration. Besides, it is essential to minimize drug exposure to non-target tissues to avoid potential side effects. The use of nano
DDS, such as nanoliposomes, has helped in improving drug efficacy and safety by modifying the pharmacokinetic properties, for instance, distribution, absorption, and elimination of the drug (Mozetič, 2019). Their small particle size range enables systemic administration because the smallest blood capillaries are 10$20 \mu \mathrm{m}$ in diameter (Zamani et al., 2018). Further, carriers in this size range could be used for targeted delivery of different types of therapeutic payloads to specific organs and tissues (Moku et al., 2019). In recent years the problem of phagocytic removal of nanoparticles has been solved by surface modification of nanoparticles. The surface modification protected nanoparticles from being phagocytosed and removed from the blood vascular system after intravenous injections (Mahapatro and Singh, 2011). However, nanoliposomes are like biological membranes and are more suitable for cellular absorption. It has been reported that phospholipid bilayer maybe suffers oxidation damage during storage conditions (Islam Shishir et al., 2019). The surface modification of conventional nanoliposomes can enhance stability under storage conditions, improve phospholipid bilayer permeation, and protect the loaded drug (Sperling and Parak, 2010). Karim et al. (2020) reported that surface decoration of neohesperidin-loaded nanoliposome using chitosan and pectin could improve stability and controlled release. The results confirmed good encapsulation efficiency ( $>90 \%$ ), the particle size of $79.50 \pm 0.72$ with zeta potential values of $-29.63 \pm 0.81$. The modified nanoliposomes coated with chitosan (CH-NH$\mathrm{NL}$ ) and pectin (P-CH-NH-NL) were compared to conventional nanoliposomes loaded neohesperidin (NH-NL). Even though all nanoliposomal formulations exhibited mucoadhesion ability, the modified samples showed the highest mucin adsorption percentage and were more effective in preserving neohesperidin. Storage results unveiled that nanoliposomal systems can be stable for 30 days at $4^{\circ} \mathrm{C}$ in the dark condition. However, throughout the storage study, the particle size of NH-NL was higher than that of CH-NH-NL and P-CH-NH-NL. As a result, the decoration of nanoliposomes can be a promising way to improve the physicochemical stability, controlled release behavior, and mucoadhesion ability.

Similarly, modified nanoliposomes have presented potentialities as an ocular delivery system to treat glaucoma. Jin et al. (2018) investigated D-alpha-tocopheryl poly (ethylene glycol 1000) succinate (TPGS) modified nanoliposomes for brinzolamide (Brz) delivery. The average particle size was 96.87 $\pm 4.43 \mathrm{~nm}$, and the entrapment efficiency of the Brz was 95.41 $\pm 3.03 \%$. The nanoliposomes containing TPGS (T-LPs/Brz) were compared with conventional nanoliposomes loaded Brz $(\mathrm{LPs} / \mathrm{Brz})$ and the commercial formulation AZOPT $\mathbb{R}$ ( $\mathrm{Brz}$ ophthalmic suspension, Brz-Sus). Enhanced trans-corneal transport of Brz was achieved with T-LPs/Brz. Compared with Brz-Sus and LPs/Brz, the apparent permeability coefficient of TLPs/Brz was 10.2-and 1.38-folds higher, respectively. Moreover, $\mathrm{T}-\mathrm{LPs} / \mathrm{Brz}$ extended the cornea residence of Brz. The in vivo studies were performed in White New Zealand rabbits treated with T-LPs/Brz had 3.1- and 1.57-folds Brz concentration $2 \mathrm{~h}$ after treatment than Brz-Sus and LPs/ Brz, respectively. Eye irritation experiments and histological analysis demonstrated that T-LPs/Brz had not long or short-term irritant effects and did 
not induce eye inflammation. Further pharmacodynamic studies showed that T-LPs/Brz maintained an adequate intraocular pressure (IOP) reduction from 3 to $11 \mathrm{~h}$ after administration. In comparison, Brz-Sus and LPs/Brz presented significant IOP decreases from 3-6 to 3-8h, respectively. Moreover, they were stable for at least 10 days at 4 and $25^{\circ} \mathrm{C}$. Cumulatively, the results supported the conclusion that TPGS modified nanoliposomes could be an effective delivery system for Brz to treat glaucoma.

\section{Stability/Shelf Life}

Nanoliposome stability is an essential parameter in the physicochemical properties for subsequent exploitation as DDS. In terms of particle size. It is defined as the preservation of nanoparticle dimensionality during storage and/or an experiment. Moreover, the prospective therapeutic benefits of nanoliposomal-encapsulated drugs depend on their lifetime and distribution within the organism, which are factors related to their stability (Taira et al., 2004). The conservation of dimensionality depends on the homogeneity of the synthesized materials and stabilizing agents present during storage or use (Phan and Haes, 2019). For the above reasons, nanoliposomes should have adequate stability profile to preserve their sizes at a nanometric scale. An attractive feature of nanoliposomes is that they are metastable and can be diluted with water without changing their vesicle size distribution (Khorasani et al., 2018). Biomedical agents should be effectively cleared from the body to lower the accumulation in organs or tissues. Hence, nanoliposomes are required to have modest stability to make them more degradable and clearable, resulting in lower bioaccumulation and favorable risk-benefit ratios. The active surface of nanoliposomes may react with bioactive substances or cells in organisms responsible for initiating multifaceted reactions, ensuing the aggregation, dissolution, degradation, accumulation, and sedimentation. However, their stability not only depends on themselves but also is strongly related to their whole organized structure, the substances used to disperse or load them, the synthesis conditions, biological interactions, and other factors ( $\mathrm{Xu}$ et al., 2018). Highlighting these considerations, studies of physical stability, and in vitro intestinal digestibility of nanoliposomes were evaluated (Beltrán et al., 2019). Nanoliposomes were produced by microfluidization (MF) and ultrasound (US) for high oleic palm oil (HOPO) encapsulation. The average size of nanoliposomes was 141.2 \pm 1.7 to $180.0 \pm 1.2 \mathrm{~nm}$, having $0.141 \pm 0.014$ PDI for MF and $0.224 \pm 0.012$ PDI for the US while Zeta potential values from $-45.6 \pm 3.2 \mathrm{mV}$ for $\mathrm{MF}$ and $-45.9 \pm 4.0 \mathrm{mV}$ for the US were found. Zeta potential values were less than $-30 \mathrm{mV}$ being considered as coming within the range of excellent stability (Vanitha et al., 2017). No significant changes in nanoliposomes physical stability were recorded during oral phase's $2 \mathrm{~min}$, the vesicle size values remained between $139.9 \pm 2.1 \mathrm{~nm}$ and $170.0 \pm$ $1.2 \mathrm{~nm}$, with zeta potential values below $-30 \mathrm{mV}$ and PDI values of $0.186 \pm 0.027$ and $0.222 \pm 0.014$ for US and MF. However, both nanoliposome formulations experimented a high degree of destabilization during gastric phase. Finally, it was noted that US-prepared nanoliposomes became less digested that those prepared by MF, thereby indicating a greater stability of the USprepared NLs, in turn enabling greater encapsulated compound protection in the gastric phase. This was also an indicator that $\mathrm{NL}$ encapsulation could reduce the gastric hydrolysis of $\mathrm{HOPO}$ and the speed at which solubilized bioactives become degraded in gastrointestinal conditions.

Bardania et al. (2017) indicated the implementation of RGDmodified nanoliposomes (RGD-MNL) for the targeted delivery of antithrombotic drug eptifibatide. The nanoliposomes were about $90 \pm 10 \mathrm{~nm}$ in size, with an encapsulation efficiency of $37 \pm 5 \%$. The stability of nanoliposomes was evaluated by monitoring their size and drug leakage. Hence, the reported vesicle size was from $87.93 \mathrm{~nm}$ up to $114 \mathrm{~nm}$ during the storage period of 21 days at $4^{\circ} \mathrm{C}$ and leakage percentage values ranging from 0 to $4.5 \%$, which indicated long term stability. According to the results, the authors concluded that the novel formulation effectively enhanced the delivery of eptifibatide to the activated platelets compared to free drugs.

Bochicchio et al. (2017) confirmed the stability of nanoliposomes loaded with a siRNA against the transcription factor E2F1 for colorectal cancer therapy. The nanoliposomes exhibited a particle size of $40 \mathrm{~nm}$ and high homogeneity. The spectrophotometric and electrophoretic assays corroborated the stability and $100 \%$ siRNA encapsulation efficiency. No major de-complexation of siRNA from nanoliposomes occurred following the application of an electric field; this indicated the high stability of the formed complexes. The uptake study in colon tissue cultures revealed nanoliposomes' ability to penetrate and spread all over the colon mucosa tissue. Noticeably, no evident signs of cell damage were observed, thus confirming the absence of any significant toxicity. Moreover, the nanoliposome was influential in the downregulation of the target in cultured cells and the subsequent reduction of cell growth. Finally, vital uptake and target silencing efficiencies were observed in cultured human biopsy of the colon mucosa.

\section{BIOMEDICAL APPLICATIONS OF NANOLIPOSOMES}

The term nanomedicine refers to the disease treatment, diagnosis, monitoring, and control of biological systems by using nanotechnology applications, according to the National Institutes of Health (Moghimi et al., 2005). The implementation of nanostructured systems in biomedical sciences focuses on the development of new techniques for disease diagnosis, drug design, and drug delivery particles or molecules to improve the bioavailability of a drug by subjection to suitable surface modifications where the main objective is to impart them with biological properties and functionalities (Saji et al., 2010).

Nanoliposomes have been widely studied to know their interaction effects in different strains, cultures, and animal models for the development of new drugs, vaccines, improvement of photodynamic and cancer therapy, or even as a tool for the detection of several diseases. Among the current biomedical treatments, chemotherapy sensitization of glioblastoma $(75 \mathrm{~nm})$ (Papachristodoulou et al., 2019), 
gastrointestinal disorders (145 nm) (Chen et al., 2020), cutaneous $(20 \mathrm{~nm})$, and fungal infections $(100 \mathrm{~nm})$ (Saadat et al., 2016; Bhagat et al., 2019), encapsulation of calothrixin B as anticancer agent $(108 \mathrm{~nm}$ ) (Yingyuad et al., 2018) are included as some of the successful examples of nanoliposomes as drug delivery mechanisms. Figure 4 Illustrates drug administration and release pathways of nanoliposomes against cancer cells.

\section{Antifungal Potentialities of Nanoliposomes}

The number of cases related to superficial or systemic fungal infections has been increasing throughout the last three decades worldwide. Coupled with this, the current treatments to address these diseases are carried out during long periods and can present side effects, especially those for oral administration. Additionally, the lack of bioavailability, low penetration capacity, and poor drug release make it challenging to reach the target site (Taboada and Grooters, 2008; Kumar et al., 2014). To overcome these issues, a considerable range of nanotechnology-based products has been developed. Nanoliposomes are the most common phospholipid-based nanocarriers in dermal applications due to the high skin penetration capacity and efficacy of several drugs (Gupta et al., 2017). Amphotericin B, the first marketed product based liposomal formulation manufactured by Vestar Research Inc in 1990 (Shah and Misra, 2004). Several encapsulated substances, including commercial drugs and natural compounds, for the treatment of fungal infections, are presented in Table 4.

A mucoadhesive nanoliposomal formulation for vaginal delivery of ciclopirox (CPO) was prepared (Karimunnisa and Atmaram, 2013). The average size of nanoliposomes was found in the range of $196 \pm 1.73 \mathrm{~nm}$, entrapment efficiency of $44.89 \pm$ $3.2 \%$, and a zeta potential of $-56.2 \pm 1.4 \mathrm{mV}$. The antifungal activity of the CPO liposomes was confirmed against Candida albicans ATCC 10231 in comparison with pure CPO at $\mathrm{pH}$ 4.5. It was found that the pure drug showed the complete killing of Candida within $3 \mathrm{~h}$ as colonies were absent. At $3 \mathrm{~h}$, the nanoliposomes brought about a significant reduction in the number of colonies (up to $28 \pm 8$ ) compared to its initial count $(152 \pm 12)$, whereas complete eradication was observed at the end of $6 \mathrm{~h}$. The in-vitro antifungal activity testing concluded that CPO entrapped in nanoliposomes too demonstrated antifungal activity.

Risaliti et al. (2020) incorporated Artemisia annua essential oil (AEO) against Candida species (C. krusei, C. parapsilosis, C. dubliniensis, C. norvegensis, C. tropicalis, and C. albicans) in a nanoliposomal formulation (AEOL). Encapsulation efficiency was about $75 \%$, and the recovery percentage was more than $90 \%$. The nanoliposomes' performance against different Candida strains was assayed using the broth microdilution

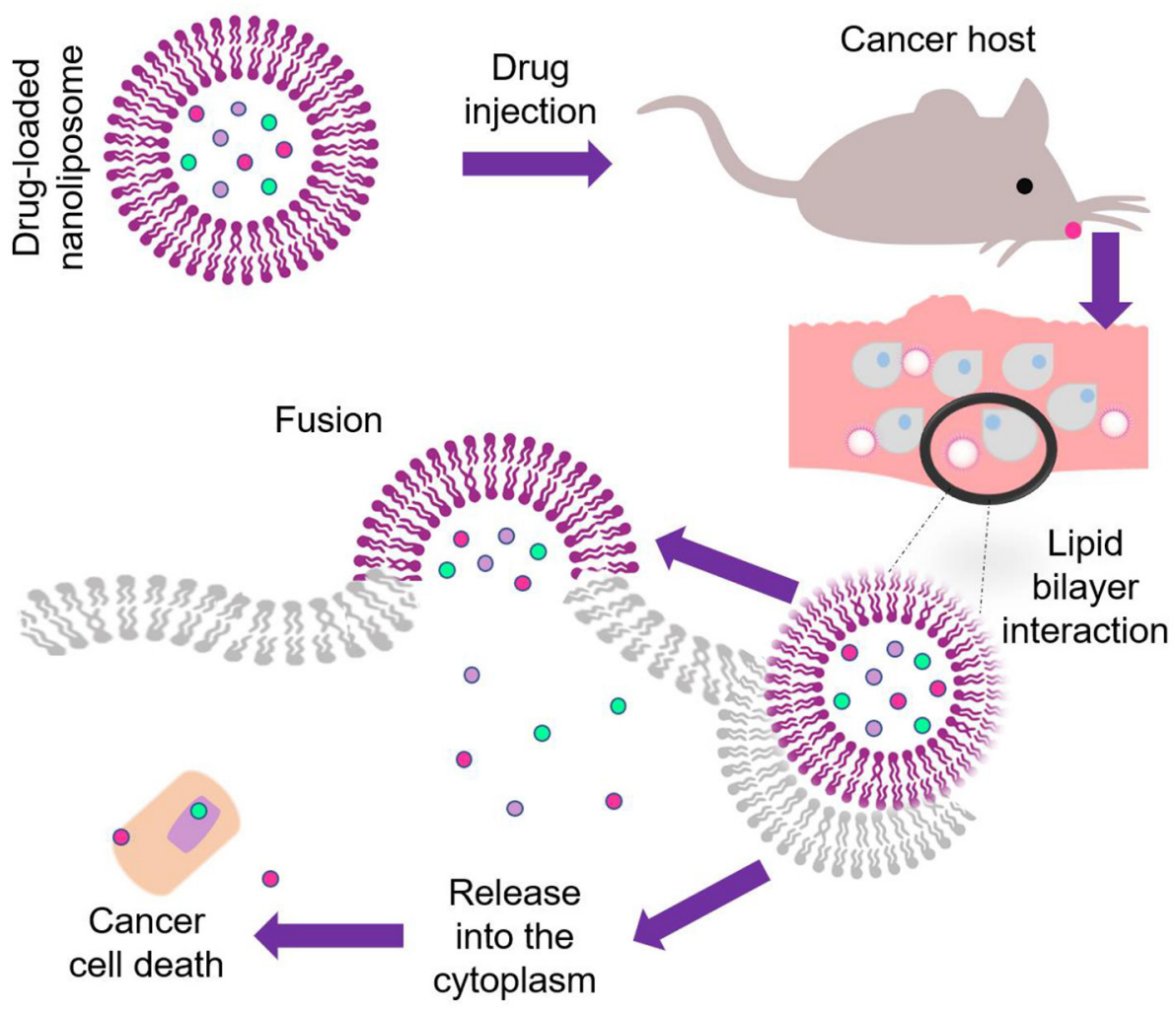

FIGURE 4 | Illustration of the drug administration and release pathway of nanoliposomes against cancer cells. 
TABLE 4 | Encapsulated substances, including commercial drugs and natural compounds, for the treatments of fungal infections.

\begin{tabular}{|c|c|c|c|}
\hline Drug/compound & Fungal infection & Findings & References \\
\hline Amphotericin B (AmB) & $\begin{array}{l}\text { Systemic fungal } \\
\text { infections and } \\
\text { leishmaniasis }\end{array}$ & $\begin{array}{l}\text { Higher accumulation values in human skin of AmB nanoliposomes and lower MIC } \\
\text { values than as commercial product AmBisome. } \\
\text { Deeper penetration in epithelial layers. }\end{array}$ & Perez et al., 2016 \\
\hline Bexarotene & Psoriasis & $\begin{array}{l}\text { Reversion of psoriasis. } \\
\text { Safety compatibility profile. } \\
\text { Controlled release for over a period of } 24 \mathrm{~h} \text {. } \\
\text { High percentage of entrapment efficiency. }\end{array}$ & Saka et al., 2020 \\
\hline Fluconazole & Aspergillosis & $\begin{array}{l}\text { Nano-fluconazole had better antifungal effects than the common form of drug on } A \text {. } \\
\text { flavus and } A \text {. fumigatus species. } \\
\text { Controlled and sustained release. Chemical stability enhancement. }\end{array}$ & Sarrafha et al., 2018 \\
\hline Fluconazole & Candida albicanis & $\begin{array}{l}\text { Controlled particle size and appropriate drug loading. } \\
\text { Superior Fluconazole entrapment and lower constant drug release compared to } \\
\text { nanoethosome formulation. } \\
\text { Potential application to prevent fungal biofilm formation }\end{array}$ & Zandi et al., 2018 \\
\hline
\end{tabular}

assay, evaluating the Minimum fungicidal concentration (MFC) $(\mathrm{mg} / \mathrm{ml} \pm \mathrm{SD})$ of AEO and AEOL prepared with RPMI-MOPS. The MFC values ranged from ca. 10 to ca. $42 \mathrm{mg} / \mathrm{ml}$ of AEO, while AEOL were tested between 5 and $10 \mathrm{mg} / \mathrm{ml}$. Among the Candida species tested, the most susceptible to AEO was $C$. norvegensis $(6.25 \mathrm{mg} / \mathrm{ml})$, followed by C. albicans and C. krusei. In comparison, the most susceptible species to AEOL was $C$. norvegensis $(5.00 \mathrm{mg} / \mathrm{ml})$, followed by $C$. krusei. These findings suggested that AEOL could optimize biological properties and defeat fungal infections. The average MFC for AEO loaded nanoliposomes was generally one-third of AEO, demonstrating the antifungal activity enhanced by nanoliposomes. To avoid the verbose effect and unnecessary literature discussion, drug-loaded nanoliposome with antifungal attributes against various fungal strains are summarized in Table 5.

\section{Skin-Curative Potential of Nanoliposomes}

Skin is the largest and the most important organ for tropical and systemic drug administration. Its action mechanism is to protect the organism from the environment, acting as a passive barrier to the penetrant molecules. However, its exposure to the environment promotes susceptibility to damage and injury. The reason behind that common lesions is related to skin (Wang et al., 2019). Stratum corneum (SC) is the main barrier of the skin, composed of 15-20 layers of dead epidermal cells. This barrier is rich in ceramides, cholesterol, and fatty acids. With these considerations in mind, nanoliposomes become suitable for potential applications in topical drug delivery. Nanoliposomes are usually implemented as penetration enhancers of active ingredients into the skin layers. Their composition allows them to create a drug reservoir when mixing with SC lipids like ceramides, thus promoting lipophilic drug permeation of the skin (González-Rodríguez and Rabasco, 2011; Rahimpour and Hamishehkar, 2012). Figure 5 illustrates the effect of a nano encapsulated compound through skin layers compared to the non-encapsulated compound. Hasanpouri et al. (2018) evaluated nanoliposomes and nanotransferosomes in the dermal delivery of tetracycline hydrochloride (TC) for acne treatment. The particle size and distribution of TC-loaded liposomal formulation were found to be $74.8 \pm 9.5 \mathrm{~nm}$ with a polydispersity index (PDI) $0.26 \pm 0.03$, while the mean zeta potential value was were $17.2 \pm 5.2 \mathrm{mV}$ indicating lack of colloidal stability due to was less than \pm 30 . However, the authors suggested the possibility of a topical aqueous gel for the final formulation dosage of the vesicular nanostructures which is in agreement with a previous study of skin-aging protection reported by Heydari et al. (2017). The in vitro drug release profile indicated that the percentage of released TC from liposomal formulation (55 $\pm 5.5 \%$ ) was higher than that of transferosomal formulation $(21.6 \pm 4.6 \%)$, indicating maintaining the drug entrapped until its delivery to the target tissue and microorganism and preventing drug leakage, in this way its advantage in superior dermal delivery probably results in better clinical outcomes. Foldvari et al. (1990) studied the fate of liposomes loaded with lidocaine and the encapsulated drug after topical application on the skin. The investigation compared the effect of lidocaine encapsulated into liposomes or incorporated into Dermabase (R) cream supplied to human volunteers about 20-25 years of age. The anesthetic effect produced by the liposome-encapsulated lidocaine was longer than the cream form and $4 \mathrm{~h}$ after the removal of the preparations the effect of liposomal lidocaine was still about two times greater than the conventional dosage form and the provided efficient analgesia of the intact skin was reflected in the measurement of high painless scores. It was also found a size restriction to penetration, because liposomes larger than about $0.7 \mu \mathrm{m}$ were not observed during the electron microscopic studies. As consequence of this study, a hypothetical mechanism of interaction of topical liposomal systems with the skin was proposed for the authors and summarized in Figure 6, as follows: 
TABLE 5 | Drug-loaded nanoliposome with antifungal attributes against various fungal strains.

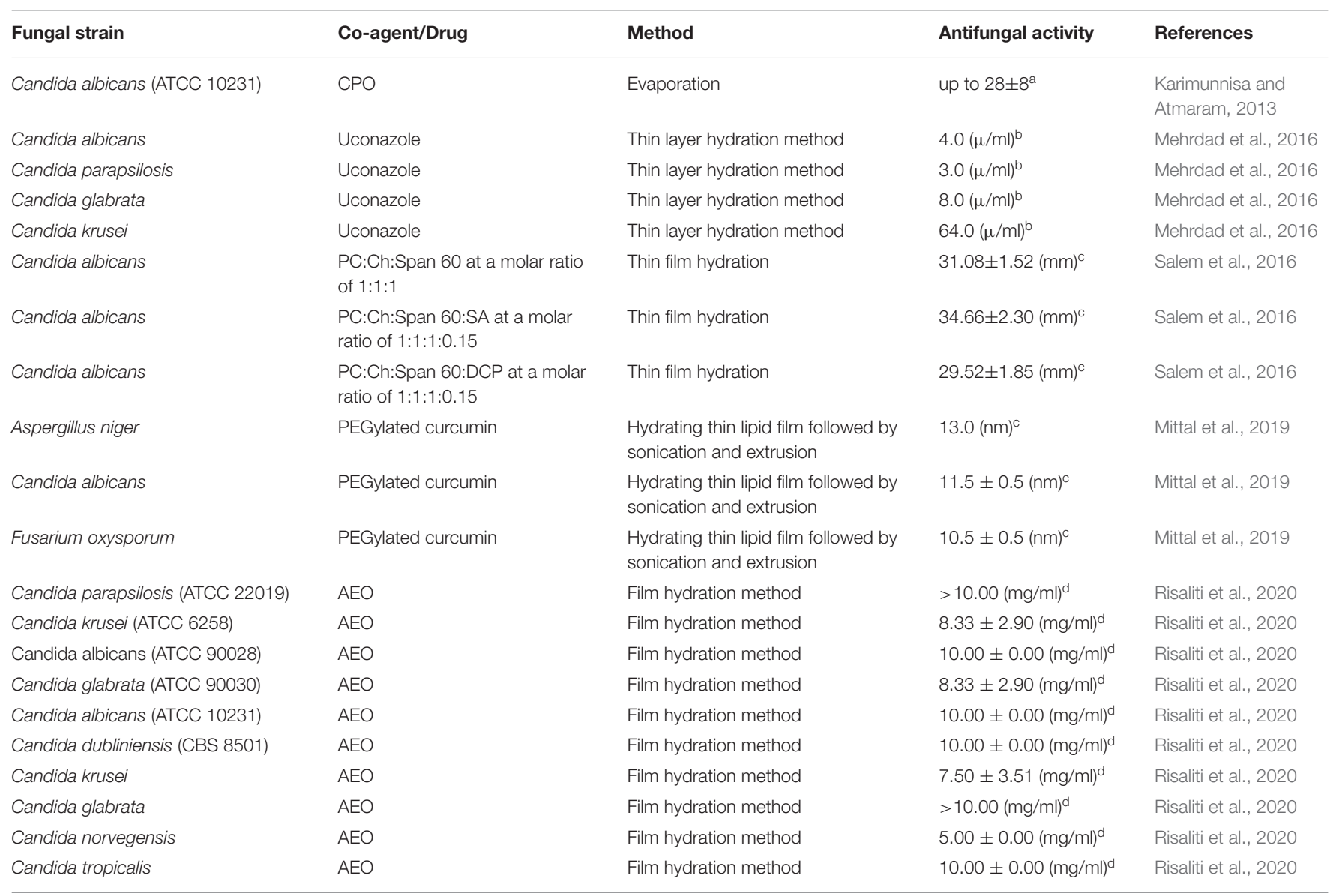

${ }^{a}$ Reduction in number of colonies, ${ }^{b} \mathrm{MIC},{ }^{c}$ Zone of inhibition, ${ }^{d} \mathrm{MFC}$.

MIC, Minimum inhibitory concentration; MFC, Minimum Fungicidal Concentration, AEO, Artemisia annua essential oil; SD, standard deviation; CPO, Ciclopirox olamine; PC, Phosphatidylcholine; Ch, Cholesterol; DCP, dicetyl phosphate.

- Liposomes can be absorbed to the skin surface intact before their penetration into the skin, either intercellular or intracellular journey.

- Some liposomes can rupture on the surface of the skin.

- The penetration of smaller vesicles is more probable. However, the intradermally localized uni- or oligolamellar vesicles may be derived from multilamellar liposomes, which lost their outer bilayers during penetration.

Regarding the previous model, size is crucial in the design and formulation of new drug delivery routes based on nanoliposomes for dermal and topical approaches. Thus, given the size range of nanoliposomes, they are promising candidates for implementing more realistic and functional target DDS in the treatment of skin diseases.

\section{Nanoliposomes Based Targeted Drug Delivery}

Targeted drug delivery can be defined as a strategy that selectively and preferentially delivers the therapeutic agents or active ingredients to a target area concurrently failing access to the non-target site, thus maximizing the effectiveness of the drug (Rahimpour and Hamishehkar, 2012; Tekade et al., 2017). Nanoliposomes are considered one of the most biocompatible nanocarriers used for targeted drug delivery because of their capacity to increase the bioavailability and biodistribution of the selected encapsulated agent site by overcoming the obstacles of cellular uptake (Joshi and Joshi, 2019).

Active or triggered mechanisms can be achieved by nanoliposomes based therapy. For the first type, the nanoliposome's surface is done by ligand and antibodies, while in triggered drug delivery, the drug release is produced via stimuli sensitive (Singh et al., 2017). Internal drug triggers include $\mathrm{pH}$, small biomolecules, enzyme or hormone level, glucose, or redox gradient related to the illness pathological aspects. External stimuli, including hyperthermia, ultrasound (US), light, and magnetic field, are also used to trigger the ill site's drug release. According to Darvin et al. (2019), a smart DDS can reach a particular site where the drug is intended to release. It can also release the drug in response to specific stimulations (e.g., temperature, light, ultrasound, $\mathrm{pH}$, magnetic, electric field, enzyme, redox). This ability makes them intelligent systems 


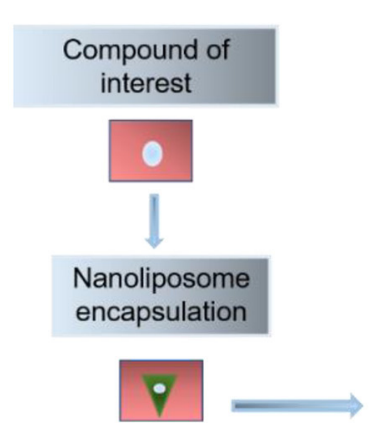

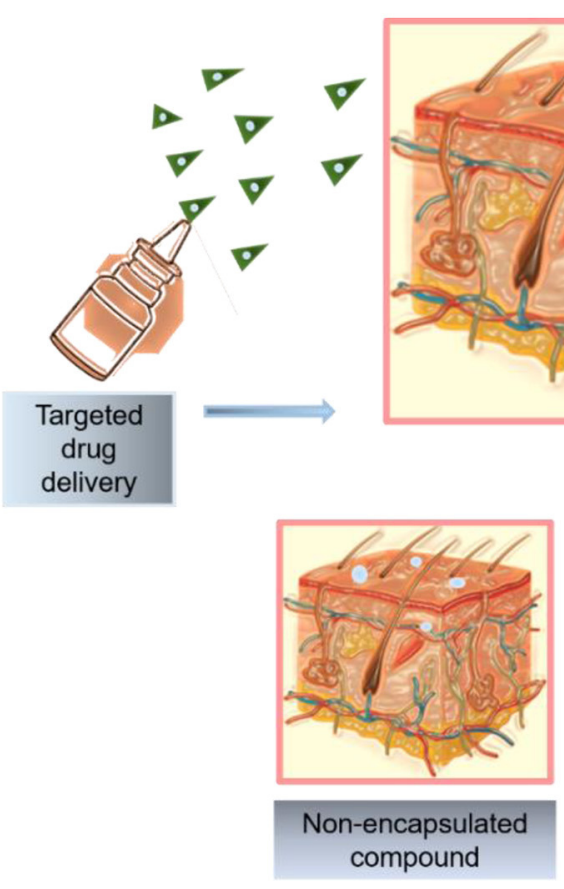

1
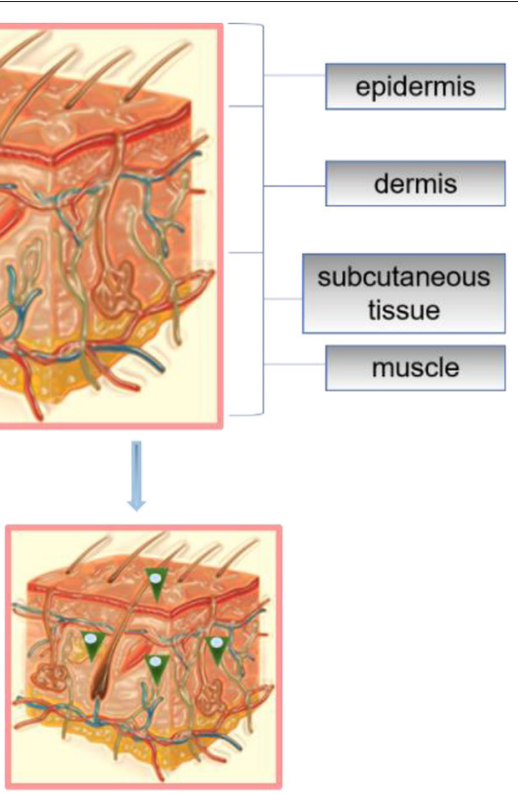

Encapsulated compound

\section{2}

FIGURE 5 | Penetration effect of a nano encapsulated compound through skin layers compared to the non-encapsulated compound. (1) shows the poor penetration effect and the lack of biodistribution across the epidermis and dermis; (2) illustrates the route of nanoliposomes into deeper skin layers.

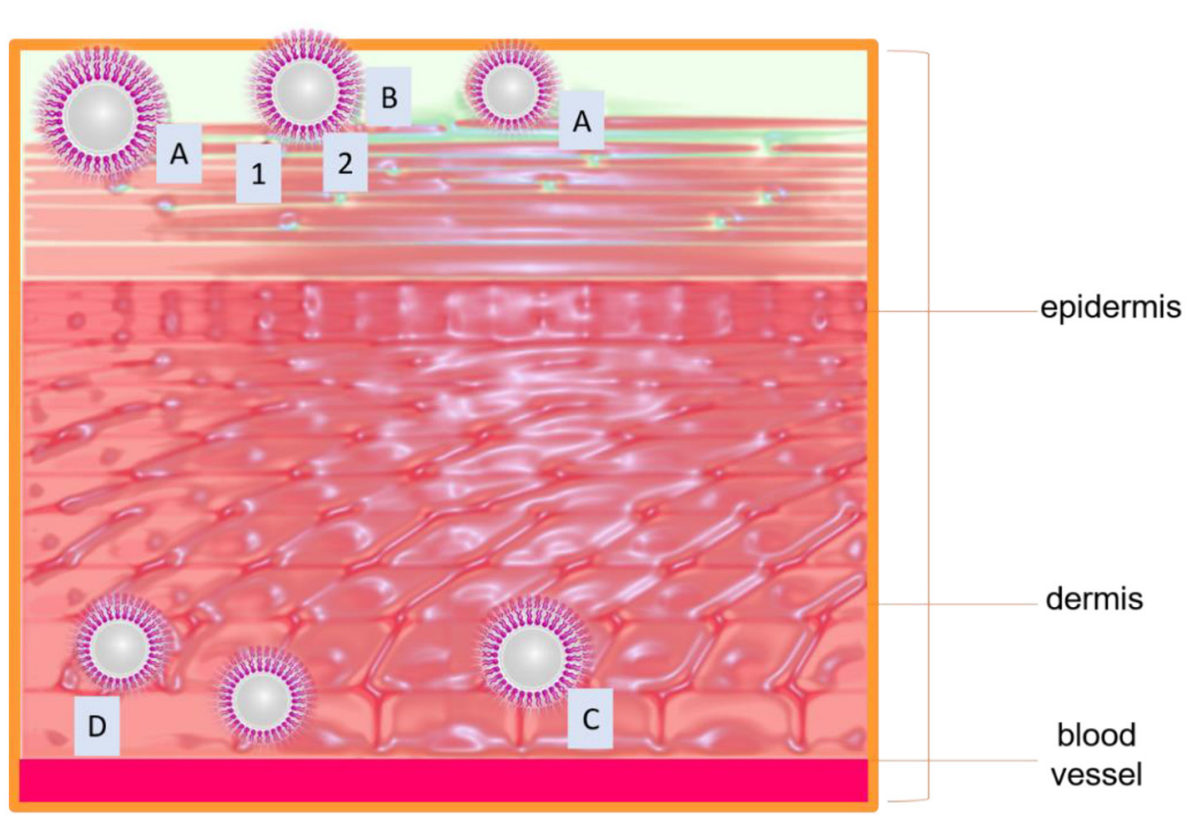

FIGURE 6 | (A) Adsorption of liposomes to the skin surface; drug transfer from liposomes to skin. (B) Rupture of vesicles, the release of content, and the penetration of the free molecules into the skin via intracellular (1) or intercellular route (2). (C) Penetration of unilamellar vesicles via the lipid-rich channels to the dermis where they slowly release their content due to disruption or degradation of liposomal membranes. (D) Penetration of multilamellar vesicles via the lipid-rich channels. On the route of penetration of multilamellar vesicle can lose one or more outer lipid lamellae which would lead to partial release of the encapsulated material. 
capable of self-regulation, integrated sensing, monitoring, and activation by the environment and stimuli (Wang and Kohane, 2017).

Chen et al. (2018) synthesized a Co-delivery of doxorubicin (DOX) and imatinib (IM) by $\mathrm{pH}$-sensitive cleavable PEGylated nanoliposomes with folate-mediated targeting to overcome multidrug resistance. The $\mathrm{pH}$-sensitive nanoliposomes were modified with cleavable TPGS analog (mPEG2000-Hz-VES) and folate (FA-PEG3350-CHEMS) co-delivery of DOX and IM. Alpha tocopheryl acid succinate (VES) was chemically conjugated to polyethylene glycol (PEG) via acid-labile hydrazone linker at $\mathrm{pH}$ 7.4. The reported design allowed the folate-bond nanoliposomes to be guided to the tumor cells through the selective overexpression of folate receptors. Upon the targeted cells approaching, the $\mathrm{pH}$-sensitive hydrazone bonds were hydrolyzed by the acidic environment. The nanoliposomes were fused on the tumor membrane to lead to the full drug release at $\mathrm{pH} 5-6$ so that the acid-sensitive drug release profile of the nanoliposomes was controlled. Folate was used to improve tumor cell selectivity and uptake efficiency. The formulation could maintain stability in blood circulation with diameters of $100 \mathrm{~nm}$, entrapment efficiency of $96.2 \pm 1.4$, and $96.9 \pm$ $1.2 \%$ for DOX and IM. Simultaneously, the zeta potential and polydispersity index values were $-20 \pm 2 \mathrm{mV}$ and $0.103 \pm 0.006$. Moreover, in vitro, pH-sensitive drug release was performed at $\mathrm{pH}$ 5.5, 6.5, and 7.4. The study revealed that under the acidic condition at $\mathrm{pH} 5.5$ for $72 \mathrm{~h}$, the releasing rate of DOX and IM from nanoliposomes increased significantly, and the cumulative release percentages of DOX and IM reached 90.73 and $92.37 \%$. Additionally, a membrane fusion assay was performed to determined pH-triggered release, using $\mathrm{R} 18$ as a probe inserted into the lipid membrane followed by fluorescence selfquenching. It was observed a gradual increase in R18 fluorescence with the decreasing $\mathrm{pH}$, attributed to the long PEG chain of DSPE-mPEG2000 hindered the $\mathrm{pH}$-sensitive release from nanoliposomes, which composed of DOPE and CHEMS, by blocking the membrane fusion between liposomes at low $\mathrm{pH}$. The designed nanoliposomes significantly enhanced anti-tumor effects both in vitro and in vivo.

A comparative study of smart ultrasound-triggered doxorubicin-loaded nanoliposomes was performed by Shalaby et al. (2020) in HeLa cells. The study compared the minimization dose of DOX and ultrasound (US) intensity in two nanoliposome systems, one of them was tailored to be responsive for US non-thermal effects (DOX-USLs), and the other was designed to be thermoresponsive (DOX-TSLs). Both systems were loaded with DOX and evaluated for in vitro tumor treatment and compared in terms of cellular uptake, cell viability, and apoptosis. Ultrasound- triggered the release of DOX from TSLs was conducted using a $0.8 \mathrm{MHz}$ ultrasound system at an intensity of $3 \mathrm{~W} / \mathrm{cm}^{2}$ while USLs at the frequency of $0.8 \mathrm{MHz}$ with a power intensity of $1 \mathrm{~W} / \mathrm{cm}^{2}$. The combined treatment showed markedly improved cellular uptake, tumor cytotoxicity, and enhanced apoptosis compared to free DOX treatment. A significant higher nuclear uptake and cytotoxic effect were observed from DOX-TSLs $(0.1 \mu \mathrm{g} / \mathrm{ml})$ compared to DOX-USLs $(0.2 \mu \mathrm{g} / \mathrm{ml})$, and the use of both systems had enhanced tumor apoptotic effect. The authors attributed the superior cytotoxic effect to the treatment with the US in both systems. US-mediated cavitation promoted membrane permeability and increased the intracellular accumulation of drugs. Additionally, the US also enabled the disruption of nanoliposomes, which facilitated DOX release and improved the therapeutic response.

Functional nanoliposomes have been implemented for enhanced mitochondria-targeted gene delivery and expression by Green et al. (2017), the nanoliposome formulation composed of dequalinium-DOTAP-DOPE (DQA80s) was used as a vector for target drug delivery and compared with a control vector (DQAsomes) in HeLa cells and dermal fibroblast. The developed nanoliposomes exhibited better stability than conventional transfection or mitochondrial agents, excellent potential for efficient intracellular uptake, and effective mitochondrial targeting in HeLa. The in vitro transfection essay suggested that DQA80s resulted in an improved transfection, with high membrane permeability able to promote the escape of the complex from the endosome compared to DQAsomes. Additionally, the complexes conformed by (DQA80s/pDNA) demonstrated higher cellular uptake, more rapid escape from endosomal membranes, and robust intra-mitochondria localization. The schematic of the formation of DQA80plexes (DQA80s/pDNA complexes) and transport of DQA80plexes to the mitochondria via the endocytosis pathway. Cho et al. (2015) confirmed the utilization of targeted fluorescent nanoliposomes to detect early cartilage damage in the posttraumatic osteoarthritis mouse model. The nanoliposomes were loaded with a fluorescent dye and conjugated to a collagen type II antibody to perform the in vivo study. The targeted nanoliposomes showed an affinity for homing to damaged articular cartilage due to the specific binding to degraded cartilage in a manner proportional to the degree of injury and showed a specificity of binding. Furthermore, the antibody-conjugated nanoliposomes exhibited potential as a targeted drug delivery tool to chondrocytes, also able to provide a non-invasive specific diagnostic method for detection and measurement of arthritic damage and can be intravenously administered. To avoid the verbose effect and unnecessary literature discussion, targeted drug delivery attributes of various drug-loaded nanoliposome are summarized in Table 6.

\section{TOXICOLOGICAL ASPECTS OF NANOSTRUCTURED SYSTEMS}

Throughout the last decades numerous types of nanostructured systems have been developed based on various components, including metal oxides, silica, carbon, nanocrystals, polymers, lipids, dendrimers, and quantum dots. Nanotoxicology investigates the interactions of nanostructures with biological systems (Ciucă et al., 2017). The biggest challenge faced by the scientific community involved in drug development is to deliver a safe and effective dosage of drugs without causing systemic toxicity (Sharma et al., 2012). For the specific case of nanoliposome formulations, they are considered as optimal 
TABLE 6 | Targeted drug delivery attributes of various drug-loaded nanoliposome.

\begin{tabular}{|c|c|c|c|c|c|}
\hline Loaded drug & Main target & Animal model & $\begin{array}{l}\text { Drug release } \\
(\%)\end{array}$ & $\begin{array}{l}\text { Release } \\
\text { time (h) }\end{array}$ & References \\
\hline Tadalafil & $\begin{array}{l}\text { Wound healing and scar } \\
\text { formation including } \\
\text { reepithelization and angiogenesis }\end{array}$ & Yes (Sprague-dawley female rats) & $47.8 \pm 5.5$ & 24 & Alwattar et al., 2020 \\
\hline Triptolide & Vascular endothelial cells & Yes (C57BL/6J wild-type male mice) & More than 90 & 480 & Lai et al., 2020 \\
\hline Teriflunomide & Rheumatoid arthritis & Yes (Female Wistar rats) & $73.21 \pm 2.1$ & 24 & Mahtab et al., 2020 \\
\hline Bevacizumab & Ocular disorders & No & $20.6 \pm 2.42$ & 40 & $\begin{array}{l}\text { Malakouti-Nejad et al., } \\
2020\end{array}$ \\
\hline Sorafenib & Liver cancer therapy & $\begin{array}{l}\text { Yes (Balb/c-nu mice) Nude mice } \\
\text { bearing tumors }\end{array}$ & - & - & Ye et al., 2020 \\
\hline Carboplatin & Brain cancer cell lines & No & 24.8 & 36 & $\begin{array}{l}\text { Hassanzadeganroudsari } \\
\text { et al., } 2019\end{array}$ \\
\hline Teriflunomide & Rheumatoid arthritis & Yes (Female Wistar rats) & $85.33 \pm 8.86$ & 24 & Mahtab et al., 2019 \\
\hline Artemether & Parenteral delivery & Yes (Swiss albino mice) & 65 & 30 & Shakeel et al., 2019 \\
\hline Lumefantrine & Parenteral delivery & Yes (Swiss albino mice) & 51 & 30 & Shakeel et al., 2019 \\
\hline Bleomycin & Tumor cells & No & $34.57 \pm 3.94$ & 48 & Chiani et al., 2018 \\
\hline Doxorubicin hydrochloride & $\begin{array}{l}\text { Head and neck squamous cell } \\
\text { carcinoma }\end{array}$ & No & 84 & 84 & Mohan et al., 2016 \\
\hline Resveratrol & $\begin{array}{l}\text { Head and neck squamous cell } \\
\text { carcinoma }\end{array}$ & No & Less than 80 & 84 & Mohan et al., 2016 \\
\hline Topotecan & Tumor cells & Yes (NUDE-Hsd:Athymic mice) & Up to 75 & 96 & Zucker et al., 2012 \\
\hline Vincristine & Tumor cells & Yes (NUDE-Hsd:Athymic mice) & Up to 60 & 96 & Zucker et al., 2012 \\
\hline Doxorubicin & Specific cells or tissue targeting & Yes (rats) & $69.91 \% \pm 1.05$ & 09 & Rudra et al., 2010 \\
\hline $\begin{array}{l}\text { Doxorubicin and } \\
\text { Phosphatidylethanolamine }\end{array}$ & Specific cells or tissue targeting & Yes (rats) & $77.07 \% \pm 1.02$ & 09 & Rudra et al., 2010 \\
\hline
\end{tabular}

carriers since phospholipids used in their preparation, such as phosphatidylcholine and phosphatidylethanolamine, are also present in natural cell membranes. However, it is imperative to consider the lipid composition and the desired application to minimize side effects. Mozafari et al. (2007) examined the cytotoxicity of anionic nanoliposomes and nucleic acids (nano lipoplexes) prepared by heating method and compared with the conventional preparation method. Cytotoxicity evaluations performed by two different assays (neutral red uptake (NRU) and 3-(4,5-dimethylthiazol-2-yl)-2,5-diphenyltetra- zolium bromide (MTT)) indicated that nanoliposomes were completely non-toxic in the cell-line tested, whereas conventional liposomes revealed significant levels of toxicity. This may be due to the presence of trace amounts of solvent applied during their preparation, which suggested further consideration of synthesis methodologies for the fabrication of nanoliposomes, mostly when organic solvents are used. These findings also indicated that nanoliposomes have great potential as nontoxic delivery vehicles in human gene therapy and drug delivery applications.

Regarding the impact of particle size on nanoliposomes' toxicity for clinical applications, particle size and size distribution are dominant factors for the stability assessment of a colloidal formulation upon storage, encapsulation efficiency, drug release profile, bio-distribution, mucoadhesion, cellular uptake, and clearance. Nevertheless, the size stability issue is more imperative for nanosystems compared to microsystems. This reason is due to the fact that DDS at the nanoscale has a larger specific surface area compared to microsystems (Danaei et al., 2018a). This would entail that more of the drug is closer to the surface of the particle compared to a larger molecule. Being at or near the surface would lead to faster drug release. Moreover, the high surface area in nanosystems such as nanoliposomes also implies that particles tend to agglomerate to minimize the energy. According to Bruinink et al. (2015), nanomaterials' agglomeration is still a controversial topic with respect to toxicity. It may be disclosed that uptake through the lung is limited to particles and agglomerates that can reach the alveolar region in the nanometer to the sub-micrometer range. Nevertheless, the incorporation of surfactants and stabilizers in nanoliposome preparation has been proposed as a good alternative to favors the electrostatic repulsion that prevents the loss of encapsulated drugs and the increase in the size of the vesicles (González-Rodríguez and Rabasco, 2011). On the other hand, one can assume that it would be advantageous to design nanoparticle systems with a large surface area to volume ratio; however, toxicity must always be tracked. The size of the nanoparticle determined the biological fate and, coupled with the PDI, are the main physicochemical attributes that influence the endocytosis-dependent cellular uptake. Cellular uptake of small molecules and particles depends mainly on endocytosis, and the two main mechanisms are reported to be pinocytosis and phagocytosis. Physiological processes such as hepatic uptake and accumulation, tissue diffusion, tissue extravasation, and kidney excretion significantly depend on particle size. In terms of nanosystems such as nanoliposomes, endothelial filtration 
can remove particles up to $150 \mathrm{~nm}$ in the liver. In contrast, particles below $10 \mathrm{~nm}$ can leave the systemic circulation via the lymph nodes (Psimadas et al., 2012). It has been reported that nanoparticles with dimensions of less than 5-10 nm are promptly cleared after systemic administration, whereas particles from 10 to $70 \mathrm{~nm}$ in diameter mostly penetrate capillary walls across the body; larger particles with dimensions of 70-200 nm regularly remain in circulation for a long period. Other reports in the literature indicate that nanosystems of less than $50 \mathrm{~nm}$ administered through intravenous injection reach the tissues faster than those of 100-200 $\mathrm{nm}$ in size and exert stronger toxic effects. If the size of the nanosystem is reduced, its contact surface will increase, and the level of oxidation and DNA damage will also rise. The size of nanoliposomes indicates their pharmaceutical behavior, that is, sizes of less than $50 \mathrm{~nm}$ quickly connect to all tissues and exert toxic effects. Nanoliposomes larger than $50 \mathrm{~nm}$ are used by the respiratory system, which stops its path to other tissues. But, organs like the liver and spleen are the main targets of oxidative stress (Ajdary et al., 2018). Moreover, the mechanism of action of the drug may vary because of the size of drug carriers. Drugs carried by micron-sized particles promote cell death mainly by necrosis, whereas nanoparticles cause cell death by apoptosis. Nanosize particles get in the cells and release the drug gradually to work on the cellular apoptotic system. However, micron-size drug carriers, because of their insufficiency of passage into the cells, could have released drugs outside the cellular environment, causing high local drug concentration, leading to cellular necrosis (Mukherjee et al., 2016). Shakeel et al. (2019) described the in vivo and in vitro evaluation of artemether and lumefantrine co-loaded nanoliposomes with the particle size of $112 \mathrm{~nm}$ for parenteral delivery. The toxicological examination suggested no significant evidence of renal and hepatic toxicity in tested animals. It was deduced that nanoliposomes could improve the availability of artemether and lumefantrine by prolonging drug retention in vivo. Yang et al. (2019) evaluated lapatinib and doxorubicin co-loaded in PEGylated nanoliposomes with an average size of $100 \mathrm{~nm}$ in two human lung adenocarcinoma cell lines. The formulation exhibited negligible toxicity to somatic cells, indicating the significantly reduced side effects. Besides, a decrease in toxicity was observed compared to a DOX loaded liposomal formulation and free DOX at higher concentrations. The DOX dose in the nanoliposome formulation was half of that in the comparative samples. Also, it could still maintain therapeutic efficacy and side effects reduction. On the other hand, the previous investigation accomplished by Tuerdi et al. (2016) reported the improvement of therapeutic effects of simvastatin (SMV) loaded nanoliposomes (SMV-Lipo). However, in another report published by Tuerdi et al. (2020), it was found that SMV-Lipo $(121 \pm 5.5 \mathrm{~nm})$ induced myocardial and hepatic toxicities due to its absorption enhancement in mice. The organ toxicity was evaluated in presence and absence of isoproterenol and compared to those of free SMV. Results demonstrated that compared to free SMV, the SMV-Lipo administrated at an equal dose of $25 \mathrm{mg} / \mathrm{kg} / \mathrm{d}$ led to severe myocardiotoxicity, hepatotoxicity at baseline and more pronounced liver injury with elevation of alanine aminotransferase. Muscular adverse effect was also observed in SMV-Lipo treated group but not in
SMV group. Despite of the studies revealed that compared to free SMV, the SMV-Lipo administration significantly improved the plasma SMV concentration, and the oral bioavailability was 6.5 times of free SMV. Remarkably, when the dosage of free SMV increased to $50 \mathrm{mg} / \mathrm{kg} / \mathrm{d}$, yielding the comparable plasma concentration as SMV-Lipo given at $25 \mathrm{mg} / \mathrm{kg} / \mathrm{d}$, the myocardiotoxicity was observed in free SMV treated mice as well, which further confirmed that the enhanced absorption of SMV by the nanoliposomal formulation resulted in more severe myocardiotoxicity than the equal dose of free SMV. These findings suggest that besides particle size, toxicity must be address by considering some others physicochemical factors such as absorption capacity that affect the composition and performance of nanoliposomes for drug delivery purposes.

Besides, the implementation of analytical techniques for toxicity evaluation has allowed monitoring the in vivo fate of nanoliposomes. Being quantitative methods, such as fluorescence labeling, radiolabeling, magnetic resonance imaging (MRI), mass spectrometry, and computed tomography (CT) some of the most used given their specificity and excellent sensitivity (Rizvi and Saleh, 2018; Su et al., 2018). However, further in vitro and in vivo research under different conditions is still necessary to evaluate the toxicity of nanoliposomes prior to clinical applications.

\section{COMPATIBILITY-PATIENT COMPLIANCE AND SAFETY}

Drugs-based liposomes have already been successfully tested in humans and approved by FDA, examples include DepoDur (R), Lipusu $($, Exparel, among others (Beltrán-Gracia et al., 2019). Exparel ( $\mathrm{R}$ is a bupivacaine liposome injectable suspension $(3,000-30,000 \mathrm{~nm})$ developed by Pacira Pharmaceuticals $\mathrm{R}$, Inc. and approved in 2011 by FDA. The suspension is indicated for postoperative pain after hemorrhoidectomy and bunionectomy. Mont et al. (2018) compared the effects of local infiltration analgesia (LIA) with liposomal bupivacaine (LB) in patients undergoing total knee arthroplasty (TKA) where a total number of 140 patients, including adult men and non-pregnant women were randomized to LIA with LB

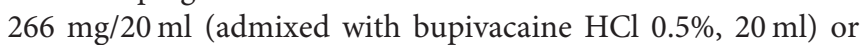
LIA with bupivacaine $\mathrm{HCl} 0.5 \%, 20 \mathrm{ml}$. Standardized infiltration techniques and a standardized multimodal pain management protocol were used. The coprimary efficacy endpoints were area under the curve (AUC) of visual analog scale pain intensity scores $12-48 \mathrm{~h}$ (AUC12-48) post-surgery and total opioid consumption $0-48 \mathrm{~h}$ post-surgery. Results showed that an opioid-sparing multimodal pain management approach using LIA with LB could safely manage pain while further reducing or eliminating the need for opioids following TKA, which also could have a. In this setting, LIA with LB significantly improved postsurgical pain, opioid consumption, and time to first opioid rescue, with more opioid-free patients and no unexpected safety concerns.

Concerning the clinical trials with formulations basednanoliposomes, one of the most recent drugs-based approved by the FDA in 2017 is VYXEOS $(100 \mathrm{~nm})$, a combination 
of daunorubicin-cytarabine developed by Jazz Pharmaceuticals, Inc. (Beltrán-Gracia et al., 2019) for the treatment of adults with newly diagnosed therapy-related AML (t-AML) or AML with myelodysplasia related changes (AML-MRC), two types of AML having a poor prognosis, being the first FDA-approved treatment for this specific type of sickness (FDA, 2017). For the clinical phase 3 test, 309 patients 60-75 years of age with newly-diagnosed t-AML or AML-MRC through a randomized (1:1), multicenter, open-label, and active-controlled trial study comparing VYXEOS to a classic combination of daunorubicin and cytarabine $(7+3)$ administrated intravenously, where it was demonstrated that VYXEOS had an estimated median overall survival of 9.6 months compared with 5.9 months for the $7+3$ control (hazard ratio 0.69; 95\% CI: 0.52, 0.90; $p=0.005$ ). Moreover, VYXEOS nanoliposomes exhibited a prolonged plasma half-life following intravenous infusion, with greater than $99 \%$ of the daunorubicin and cytarabine in the plasma remaining encapsulated within the nanoliposomes, which accumulate and persist in high concentration in the bone marrow, where they are preferentially taken up intact by leukemia cells in an active engulfment process (Jazz Pharmaceuticals UK, 2019).

Another drug tested and approved by FDA is AmBisome $\mathbb{R}$ (Gilead Sciences, 2012). AmBisome (R) is a nanoliposome formulation with a reported vesicle size of $45-80 \mathrm{~nm}$, administrated by intravenous fusion. The formulation is indicated for empirical therapy for presumed fungal infection in febrile, neutropenic patients. Eleven clinical studies were conducted to support its efficacy and safety in patients with Aspergillus species, Candida species and/or Cryptococcus species infections and visceral Leishmaniasis. These patients either had fungal infections refractory to amphotericin B deoxycholate, were intolerant to the use of amphotericin B deoxycholate, or had pre-existing renal insufficiency. Patient recruitment involved 140 infectious episodes in 133 patients, with 53 episodes evaluated for mycological response and 91 episodes assessed for clinical outcome. Clinical success and mycological eradication occurred in some patients with documented aspergillosis, candidiasis, and cryptococcosis. Regarding the treatment of Leishmaniasis, AmbiSome $(\mathrm{R}$ achieved high rates of acute parasite clearance when total doses of $12-30 \mathrm{mg} / \mathrm{kg}$ were administered in immunocompetent patients. Most of these immunocompetent patients remained relapse-free during follow-up periods of 6 months or longer. While acute parasite clearance was achieved in most of the immunocompromised patients who received total doses of $30-40 \mathrm{mg} / \mathrm{kg}$, most of these patients were observed to relapse in the 6 months following the completion of therapy. When followed for 6 months or more after treatment, the overall success rate among immunocompetent patients was $96.5 \%$, and the overall success rate among immunocompromised patients was $11.8 \%$ due to relapse in most patients. There are no data documenting the efficacy or safety of repeat courses of AmBisome or maintenance therapy with this drug among immunocompromised patients.

Onivyde, also known as MM-398 or PEP02, is a nanoliposomal formulation of irinotecan $(88 \sim 95 \mathrm{~nm})$ in diameter (Drummond et al., 2006) which has demonstrated promising anticancer activity across a broad spectrum of malignancies, including pancreatic cancer, esophagogastric cancer, and colorectal cancer (Zhang, 2016). The nanoliposomal formulation of irinotecan occupies a modified gradient-loading method using sucrose octasulfate with unparalleled drug-loading efficiency and in vivo drug stability. A phase I study carried out by Chang et al. (2015) reported the dose limiting-limiting toxicity (DLT), maximum tolerated dose (MTD), and pharmacokinetics (PK) of PEP02 in patients with advance refractory solid tumors. It was found that myelosuppression and diarrhea were the major DLTs, and $120 \mathrm{mg} / \mathrm{m}^{2}$ was defined as the MTD. Pharmacokinetic analysis displayed that the release of free-form irinotecan from the nanoliposomes occurred slowly over time, the toxicity pattern was comparable with that of free-form irinotecan. Moreover, encouraging antitumor activities were noticed in patients who were refractory to available treatments. Furthermore, according to the database available on the FDA website, exist a variety of orphan drugs-based liposomes that have been approved for their commercial distribution and are summarized in Table 7.

\section{LIMITATIONS, RESEARCH GAPS, AND CHALLENGES}

Despite the significant advantages of nanoliposomes used in biomedical applications, further research is needed to improve their storage stability and overall efficacy. This typical behavior is attributed to the small vesicle size and high surface energy, which entails larger van der Waals attraction forces, thus, promoting high attraction among nanoliposomes (Dahman, 2017). Several research groups have been proposed alternatives to overcome these issues, such as the addition of surfactants or polyols to stabilize the nano liposomal suspensions (Mortazavi et al., 2007; Ebrahimifar et al., 2017; Eh Suk and Misran, 2017).

Additionally, bilayer fusion and drug leakage in nanoliposomes are other issues in terms of physical stability, which can entail a low yield of shelf life of nanoliposomes, affecting the low reproducibility and stability of nanoliposomes. However, when a nanoliposomal formulation is well-prepared, fusion is not common over time (Nounou et al., 2008; Wang et al., 2019). Besides, future research focused on cytotoxicity and in vitro essays must guarantee that topical and oral administration will have adequate stability and sustained drug release profiles for practical use and not only under ideal experimental conditions (Mordorski et al., 2016). Finally, the enhancement of the fabrication techniques is another challenge that research groups must attend by developing process with high scalability, reproducibility, and economically viable, also including more responsible practices with the environment that can be achieved by avoiding or reducing the use of organic solvents and detergents, as well as the incorporation of materials such as phospholipids and excipients that are in accordance with the purpose of the final product (Danaei et al., 2018b).

\section{CONCLUDING REMARKS AND OUTLOOK}

Nanoliposomes display a broad field of nanomedicine opportunities, from their implementation as diagnostic tools 
TABLE 7 | Orphan products-based liposomes designated and/or approved by FDA, US Food and Drug Administration. https://www.fda.gov/(accessed on 30/04/2020).

\begin{tabular}{|c|c|c|c|c|}
\hline Generic name & Trade name & Designated indication & $\begin{array}{l}\text { Marketing approved } \\
\text { indication }\end{array}$ & Sponsor \\
\hline Doxorubicin HCL liposome injection & Doxil & Multiple myeloma & $\begin{array}{l}\text { Patients with multiple } \\
\text { myeloma. }\end{array}$ & $\begin{array}{l}\text { Johnson and Johnson } \\
\text { Pharmaceutical Research } \\
\text { and Dev. }\end{array}$ \\
\hline Amphotericin B lipid complex & Abelcet & Invasive fungal infections. & $\begin{array}{l}\text { Patients intolerant to } \\
\text { conventional amphotericin B } \\
\text { therapy. }\end{array}$ & Liposome Company, Inc. \\
\hline Liposomal amphotericin B & AmBisome & Visceral leishmaniasis. & $\begin{array}{l}\text { Treatment of visceral } \\
\text { leishmaniasis. }\end{array}$ & Fujisawa USA, Inc. \\
\hline Daunorubicin citrate liposome injection & DaunoXome & HIV-associated Kaposi's sarcoma. & $\begin{array}{l}\text { Advanced, HIV related } \\
\text { Kaposi's sarcoma. }\end{array}$ & $\begin{array}{l}\text { NeXstar Pharmaceuticals, } \\
\text { Inc }\end{array}$ \\
\hline Gentamicin liposome injection & Maitec & $\begin{array}{l}\text { Mycobacterium avium-intracellulare } \\
\text { infection. }\end{array}$ & N/A & Liposome Company, Inc. \\
\hline Liposomal nystatin & Nyotran & Invasive fungal infections. & N/A & The University of Texas \\
\hline Cisplatin in liposomal formulation & $\begin{array}{l}\text { SLIT Cisplatin for } \\
\text { inhalation }\end{array}$ & $\begin{array}{l}\text { Osteogenic sarcoma metastatic to } \\
\text { the lung }\end{array}$ & N/A & Transave, Inc. \\
\hline Doxorubicin liposome & Doxil & Ovarian cancer & $\begin{array}{l}\text { Refractory disease to } \\
\text { paclitaxel- and platinum }\end{array}$ & Alza Corporation \\
\hline Cytarabine liposomal & DepoCyt & Neoplastic meningitis & $\begin{array}{l}\text { Intrathecal treatment of } \\
\text { lymphomatous meningitis }\end{array}$ & Pacira Pharmaceuticals, Inc. \\
\hline $\begin{array}{l}\text { Adeno-associated vector lipoprotein lipase } \\
\text { protein }\end{array}$ & $\mathrm{N} / \mathrm{A}$ & Lipoprotein lipase deficiency & N/A & $\begin{array}{l}\text { Amsterdam Molecular } \\
\text { Therapeutics BV }\end{array}$ \\
\hline Liposomal cyclosporin A & $\begin{array}{l}\text { Liposomal } \\
\text { cyclosporin A }\end{array}$ & $\begin{array}{l}\text { Lung allograft and pulmonary } \\
\text { rejection }\end{array}$ & N/A & Vernon Knight, M.D. \\
\hline $\begin{array}{l}\text { Liposomal N-Acetylglucosminyl-N- } \\
\text { Acetylmuramly-L-Ala-D-isoGIn-L-Ala } \\
\text {-gylcerolidpalmitoyl }\end{array}$ & ImmTher & $\begin{array}{l}\text { Osteosarcoma } \\
\text { Ewing's sarcoma }\end{array}$ & N/A & Endorex Corp. \\
\hline $\begin{array}{l}\text { Liposome encapsulated recombinant } \\
\text { interleukin-2 }\end{array}$ & $\mathrm{N} / \mathrm{A}$ & $\begin{array}{l}\text { Brain and central nervous system } \\
\text { (CNS) tumors. } \\
\text { Cancers of kidney and renal pelvis }\end{array}$ & N/A & Oncothyreon Canada, Inc \\
\hline $\begin{array}{l}\text { Liposomal-cis-bis-neodecanoato-trans-R, } \\
\text { R-1,2-diaminocyclohexane-Pt (II) }\end{array}$ & Aroplatin & Malignant mesothelioma. & N/A & Antigenics Incorporated \\
\hline $\begin{array}{l}\text { Bupivacaine liposome injectable } \\
\text { suspension }\end{array}$ & Exparel & Nerve Block for Regional Analgesia & N/A & PaciraPharmaceuticals, Inc. \\
\hline
\end{tabular}

until drug carriers of topical and systemic treatments. Overall they hold great potential to innovate the area of drug delivery. Therefore described, nanoliposomes have also been satisfactorily used in drug improvement of vaccines and for the treatment of several fungal and bacterial infections, inflammation, and anticancer agents regarding their multiple utilitarian properties such as large surface as a consequence of their small size. Moreover, nanoliposomes' ability to permeate skin and blood barriers entails a better sustained-release activity and selective accumulation of active compounds within tissues providing accuracy in drug targeting. Nevertheless, nanoliposomes' broad spectrum of benefits still lacks human clinical trials and more 
efficient fabrication techniques, which are necessary to ensure scalability and translatability from the laboratory conditions to marketed products. Additional studies are needed to explore significative risks for toxicity and implement regulations for responsible management, storage, and waste disposal during the fabrication processes.

\section{AUTHOR CONTRIBUTIONS}

KA-P and HI: conceptualization. KA-P and JA-C: writingoriginal draft preparation. DM, RP-S, and HI: writing-review

\section{REFERENCES}

Ajdary, M., Moosavi, M. A., Rahmati, M., Falahati, M., Mahboubi, M., Mandegary, A., et al. (2018). Health concerns of various nanoparticles: a review of their in vitro and in vivo toxicity. Nanomaterials 8:634. doi: 10.3390/nano80 90634

Allen, T. M., and Cullis, P. R. (2013). Liposomal drug delivery systems: from concept to clinical applications. Adv. Drug Deliv. Rev. 65, 36-48. doi: 10.1016/j.addr.2012.09.037

Alwattar, J. K., Chouaib, R., Khalil, A., and Mehanna, M. M. (2020). A novel multifaceted approach for wound healing: optimization and in vivo evaluation of spray dried tadalafil loaded pro-nanoliposomal powder. Int. J. Pharm. 587:119647. doi: 10.1016/j.ijpharm.2020.119647

Arshad, M., Pradhan, R. A., Zubair, M., and Ullah, A. (2020). Lipidderived renewable amphiphilic nanocarriers for drug delivery, biopolymer-based formulations: biomedical and food applications," in Biopolymer-Based Formulations (Cambridge, MA: Elsevier), 283-310. doi: 10.1016/B978-0-12-816897-4.00013-8

Bangham, A. D., Standish, M. M., and Watkins, J. C. (1965). Diffusion of univalent ions across the lamellae of swollen phospholipids. J. Mol. Biol. 13, 238-252. doi: 10.1016/S0022-2836(65)80093-6

Bardania, H., Shojaosadati, S. A., Kobarfard, F., Dorkoosh, F., Zadeh, M. E., Naraki, M., et al. (2017). Encapsulation of eptifibatide in RGD-modified nanoliposomes improves platelet aggregation inhibitory activity. J. Thromb. Thromb. 43, 184-193. doi: 10.1007/s11239-016-1440-6

Batzri, S., and Korn, E. D. (1973). Single bilayer liposomes prepared without sonication. BBA Biomembr. 298, 1015-1019. doi: 10.1016/0005-2736(73)90408-2

Beltrán, J. D., Sandoval-Cuellar, C. E., Bauer, K., and Quintanilla-Carvajal, M. X. (2019). In-vitro digestion of high-oleic palm oil nanoliposomes prepared with unpurified soy lecithin: physical stability and nano-liposome digestibility. Colloids Surf. A Physicochem. Eng. Aspects 578:123603. doi: 10.1016/j.colsurfa.2019.123603

Beltrán-Gracia, E., López-Camacho, A., Higuera-Ciapara, I., VelázquezFernández, J. B., and Vallejo-Cardona, A. A. (2019). Nanomedicine review: clinical developments in liposomal applications. Cancer Nanotechnol. 10:11. doi: 10.1186/s12645-019-0055-y

Bhagat, S., Parikh, Y., Singh, S., and Sengupta, S. (2019). A novel nanoliposomal formulation of the FDA approved drug Halofantrine causes cell death of Leishmania donovani promastigotes in vitro. Colloids Surf. A Physicochem. Eng. Aspects 582:123852. doi: 10.1016/j.colsurfa.2019.123852

Bochicchio, S., Dapas, B., Russo, I., Ciacci, C., Piazza, O., de Smedt, S., et al. (2017). In vitro and ex vivo delivery of tailored siRNA-nanoliposomes for E2F1 silencing as a potential therapy for colorectal cancer. Int. J. Pharm. 525, 377-387. doi: 10.1016/j.ijpharm.2017.02.020

Bruinink, A., Wang, J., and Wick, P. (2015). Effect of particle agglomeration in nanotoxicology. Arch. Toxicol. 89, 659-675. doi: 10.1007/s00204-015-1460-6

Cabrera, I., Abasolo, I., Corchero, J. L., Elizondo, E., Gil, P. R., Moreno, E., et al. (2016). $\alpha$-galactosidase-A loaded-nanoliposomes with enhanced enzymatic activity and intracellular penetration. Adv. Healthc. Mater. 5, 829-840. doi: 10.1002/adhm.201500746 and editing. HI: supervision. All authors contributed to the article and approved the submitted version.

\section{ACKNOWLEDGMENTS}

The literature contents covered in this review were solely conceptualized and expressly written by the listed author(s). The listed author(s) are much obliged to their representative institutes and universities for providing the literature services.

Campardelli, R., Baldino, L., and Reverchon, E. (2015). Supercritical fluids applications in nanomedicine. J. Supercrit. Fluids 101, 193-214. doi: 10.1016/j.supflu.2015.01.030

Chang, T. C., Shiah, H. S., Yang, C. H., Yeh, K. H., Cheng, A. L., Shen, B. N., et al. (2015). Phase i study of nanoliposomal irinotecan (PEP02) in advanced solid tumor patients. Cancer Chemother. Pharmacol. 75, 579-586. doi: 10.1007/s00280-014-2671-x

Chen, Y., Cheng, Y., Zhao, P., Zhang, S., Li, M., He, C., et al. (2018). Co-delivery of doxorubicin and imatinib by $\mathrm{pH}$ sensitive cleavable PEGylated nanoliposomes with folate-mediated targeting to overcome multidrug resistance. Int. J. Pharm. 542, 266-279. doi: 10.1016/j.ijpharm.2018.03.024

Chen, Y., Xia, G., Zhao, Z., Xue, F., Gu, Y., Chen, C., et al. (2020). 7,8-Dihydroxyflavone nano-liposomes decorated by crosslinked and glycosylated lactoferrin: storage stability, antioxidant activity, in vitro release, gastrointestinal digestion and transport in Caco-2 cell monolayers. J. Funct. Foods 65:103742. doi: 10.1016/j.jff.2019.103742

Chiani, M., Norouzian, D., Shokrgozar, M. A., Azadmanesh, K., Najmafshar, A., Mehrabi, M. R., et al. (2018). Folic acid conjugated nanoliposomes as promising carriers for targeted delivery of bleomycin. Artif. Cells Nanomed. Biotechnol. 46, 757-763. doi: 10.1080/21691401.2017.1337029

Cho, H., Pinkhassik, E., David, V., Stuart, J. M., and Hasty, K. A. (2015). Detection of early cartilage damage using targeted nanosomes in a post-traumatic osteoarthritis mouse model. Nanomedicine 11, 939-946. doi: 10.1016/j.nano.2015.01.011

Ciaglia, E., Montella, F., Trucillo, P., Ciardulli, M. C., Di Pietro, P., Amodio, G., et al. (2019). A bioavailability study on microbeads and nanoliposomes fabricated by dense carbon dioxide technologies using humanprimary monocytes and flow cytometry assay. Int. J. Pharm. 570:118686. doi: 10.1016/j.ijpharm.2019.118686

Ciucǎ, A. G., Grecu, C. I., Rotărescu, P., Gheorghe, I., Bolocan, A., Grumezescu, A. M., et al. (2017). "Chapter 30 - Nanostructures for drug delivery: pharmacokinetic and toxicological aspects," in Nanostructures for Drug Delivery (Cambridge, MA: Elsevier), 941-957. doi: 10.1016/B978-0-323-46143-6.00030-0

Colas, J. C., Shi, W., Rao, V. S. N. M., Omri, A., Mozafari, M. R., and Singh, H. (2007). Microscopical investigations of nisin-loaded nanoliposomes prepared by Mozafari method and their bacterial targeting. Micron 38, 841-847. doi: 10.1016/j.micron.2007.06.013

da Rosa, F. C., Buque Pardinho, R., Schultz Moreira, M. E., de Souza, L. G. T., de Moraes Flores, É. M., Mortari, S. R., et al. (2019). In vitro stability of arsenic trioxide-liposome encapsulates for acute promyelocytic leukemia treatment. Leuk. Res. 76, 11-14. doi: 10.1016/j.leukres.2018.11.008

Dahman, Y. (2017). "Nanoparticles (Chapter 5)," in Nanotechnology and Functional Materials for Engineers A volume in Micro and Nano Technologies (Cambridge, MA: Elsevier), 93-119. doi: 10.1016/B978-0-323-51256-5.00005-8

Danaei, M., Dehghankhold, M., Ataei, S., Hasanzadeh Davarani, F., Javanmard, R., Dokhani, A., et al. (2018a). Impact of particle size and polydispersity index on the clinical applications of lipidic nanocarrier systems. Pharmaceutics 10:57. doi: 10.3390/pharmaceutics10020057

Danaei, M., Kalantari, M., Raji, M., Samareh Fekri, H., Saber, R., Asnani, G. P., et al. (2018b). Probing nanoliposomes using single particle analytical techniques: 
effect of excipients, solvents, phase transition and zeta potential. Heliyon 4:e01088. doi: 10.1016/j.heliyon.2018.e01088

Dang, Y., and Guan, J. (2020). Smart materials in medicine nanoparticle-based drug delivery systems for cancer therapy. Smart Mater. Med. 1, 10-19. doi: $10.1016 /$ j.smaim.2020.04.001

Darvin, P., Chandrasekharan, A., and Santhosh Kumar, T. R. (2019). Introduction to smart drug delivery systems. Biomimetic Nanoeng. Mater. Adv. Drug Deliv. 7, 1261-1265. doi: 10.1016/B978-0-12-814944-7.00001-1

de Matos, S. P., Lucca, L. G., and Koester, L. S. (2019). Essential oils in nanostructured systems: challenges in preparation and analytical methods. Talanta 195, 204-214. doi: 10.1016/j.talanta.2018.11.029

Debenedetti, P. G., Tom, J. W., Kwauk, X., and Yeo, S. D. (1993). Rapid expansion of supercritical solutions (ress): fundamentals and applications. Fluid Phase Equilib. 82, 311-321. doi: 10.1016/0378-3812(93)87155-T

Demirci, M., Caglar, M. Y., Cakir, B., and Gülseren, I. (2017). "Encapsulation by nanoliposomes," in Nanoencapsulation Technologies for the Food and Nutraceutical Industries, ed S. M. Jafari (London: Academic Press), 74-113. doi: 10.1016/B978-0-12-809436-5.00003-3

Drummond, D. C., Noble, C. O., Guo, Z., Hayes, M. E., Connolly-Ingram, C., Gabriel, B. S., et al. (2010). Development of a highly stable and targetable nanoliposomal formulation of topotecan. J. Controlled Release 141, 13-21. doi: 10.1016/j.jconrel.2009.08.006

Drummond, D. C., Noble, C. O., Guo, Z., Hong, K., Park, J. W., and Kirpotin, D. B. (2006). Development of a highly active nanoliposomal irinotecan using a novel intraliposomal stabilization strategy. Cancer Res. 66, 3271-3277. doi: 10.1158/0008-5472.CAN-05-4007

Ebrahimifar, M., Nili-Ahmadabadi, A., Akbarzadeh, A., Shahemabadi, H. E., Hasanzadegan, M., Moradi-Sardareh, H., et al. (2017). Preparation, characterization and cytotoxic effects of pegylated nanoliposomal containing carboplatin on ovarian cancer cell lines. Indian J. Clin. Biochem. 32, 230-234. doi: 10.1007/s12291-016-0596-3

Eh Suk, V. R., and Misran, M. (2017). Preparation, characterization and physicochemical properties of DOPE-PEG2000 stabilized oleic acid-soy lecithin liposomes (POLL). Colloids Surf. A Physicochem. Eng. Aspects 513, 267-273. doi: 10.1016/j.colsurfa.2016.10.053

Elizondo, E., Moreno, E., Cabrera, I., Córdoba, A., Sala, S., Veciana, J., and Ventosa, N. (2011). "Liposomes and other vesicular systems: structural characteristics, methods of preparation, and use in nanomedicine," in Nanoparticles in Translational Science and Medicine. Vol. 104, ed A. Villaverde (London), 1-52.

Elsherif, N. I., Shamma, R. N., and Abdelbary, G. (2017). Terbinafine hydrochloride trans-ungual delivery via nanovesicular systems: in vitro characterization and ex vivo evaluation. AAPS PharmSciTech. 18, 551-562. doi: 10.1208/s12249-016-0528-9

Farghaly, D. A., Aboelwafa, A. A., Hamza, M. Y., and Mohamed, M. I. (2017). Topical delivery of fenoprofen calcium via elastic nano-vesicular spanlastics: optimization using experimental design and in vivo evaluation. AAPS PharmSciTech. 18, 2898-2909. doi: 10.1208/s12249-017-0771-8

FDA (2017). FDA approves liposome-encapsulated combination of daunorubicincytarabine for adults with some types of poor prognosis AML. Case Med. Res. 1-2. Available online at: https://www.fda.gov/drugs/resourcesinformation-approved-drugs/fda-approves-liposome-encapsulatedcombination-daunorubicin-cytarabine-adults-some-types-poor (accessed April, 30 2020).

Foldvari, M., Gesztes, A., and Mezei, M. (1990). Dermal drug delivery by liposome encapsulation: clinical and electron microscopic studies. J. Microencapsul. 7, 479-489. doi: 10.3109/02652049009040470

Gallez, A., Palazzo, C., Blacher, S., Tskitishvili, E., Noël, A., Foidart, J. M., et al. (2020). Liposomes and drug-in-cyclodextrin-in-liposomes formulations encapsulating $17 \beta$-estradiol: an innovative drug delivery system that prevents the activation of the membrane-initiated steroid signaling (MISS) of estrogen receptor $\alpha$. Int. J. Pharm. 573:118861. doi: 10.1016/j.ijpharm.2019. 118861

Gelfuso, G. M., Ferreira-Nunes, R., Dalmolin, L. F., Ana, A. C., dos Santos, G. A., de, S.á, F. A. P., et al. (2020). Iontophoresis enhances voriconazole antifungal potency and corneal penetration. Int. J. Pharm. 576:118991. doi: 10.1016/j.ijpharm.2019.118991
Gilead Sciences (2012). AmBisome Liposome for Injection. Gilead Sciences, Inc., 1-27. Available online at: https://www.gilead.com/-/media/files/pdfs/ medicines/other/ambisome/ambisome_pi.pdf (accessed August 3, 2020)

Gomes, M. T. M. S., Santana, Á. L., Santos, D. T., and Meireles, M. A. A. (2018). Trends on the rapid expansion of supercritical solutions process applied to food and non-food industries. Recent Pat. Food Nutr. Agric. 10, 82-92. doi: 10.2174/2212798410666180925160459

González-Rodríguez, M. L., and Rabasco, A. M. (2011). Charged liposomes as carriers to enhance the permeation through the skin. Expert Opin. Drug Deliv. 8, 857-871. doi: 10.1517/17425247.2011.574610

Green, E. S., Jeong, S. H., Lee, S., Ko, K. S., Jung, M. K., Song, S. J., et al. (2017). Functional nanosome for enhanced mitochondria-targeted gene delivery and expression. Mitochondrion 37, 27-40. doi: 10.1016/j.mito.2017.06.005

Grimaldi, N., Andrade, F., Segovia, N., Ferrer-Tasies, L., Sala, S., Veciana, J., et al. (2016). Lipid-based nanovesicles for nanomedicine. Chem. Soc. Rev. 45, 6520-6545. doi: 10.1039/C6CS00409A

Gupta, R., and Xie, H. (2018). Nanoparticles in daily life: applications, toxicity and regulations. J. Environ. Pathol. Toxicol. Oncol. 37, 209-230. doi: 10.1615/JEnvironPatholToxicolOncol.2018026009

Gupta, M., Sharma, V., and Chauhan, N. S. (2017). "Promising novel nanopharmaceuticals for improving topical antifungal drug delivery," in Nano- and Microscale Drug Delivery Systems: Design and Fabrication, ed A. M. Grumezescu (Amsterdam: Elsevier Inc), 267-280 doi: 10.1016/B978-0-323-52727-9.00011-X

Hammoud, Z., Gharib, R., Fourmentin, S., Elaissari, A., and GreigeGerges, H. (2020). Drug-in-hydroxypropyl- $\beta$-cyclodextrin-in-lipoid S100/cholesterol liposomes: effect of the characteristics of essential oil components on their encapsulation and release. Int. J. Pharm. 579:119151. doi: 10.1016/j.ijpharm.2020.119151

Hasanpouri, A., Lotfipour, F., Ghanbarzadeh, S., and Hamishehkar, H. (2018). Improvement of dermal delivery of tetracycline using vesicular nanostructures. Res. Pharm. Sci. 13, 385-393. doi: 10.4103/1735-5362.236831

Hassanzadeganroudsari, M., Heydarinasab, A., Chen, P., and Soltani, M. (2019). In vitro investigation of anticancer efficacy of carboplatin-loaded PEGylated nanoliposome particles on brain cancer cell lines. J. Nanoparticle Res. 21:124. doi: 10.1007/s11051-019-4562-x

Haury, C., Bastiat, G., Kanber, E., Boudaud, D., Rossemond Ndombina, G. A., Gondé, H., et al. (2017). Recent advances in nanocarrier-loaded gels: which drug delivery technologies against which diseases? J. Controlled Release 266, 140-155. doi: 10.1016/j.jconrel.2017.09.031

Heydari, S., Ghanbarzadeh, S., Anoush, B., Ranjkesh, M., Javadzadeh, Y., Kouhsoltani, M., et al. (2017). Nanoethosomal formulation of gammaoryzanol for skin-aging protection and wrinkle improvement: a histopathological study. Drug Dev. Ind. Pharm. 43, 1154-1162. doi: 10.1080/03639045.2017.1 300169

Hofland, H. E. J., Bouwstra, J. A., Bodde, H. E., Spies, F., and Junginger, H. E. (1995). Interactions between liposomes and human stratum corneum in vitro: freeze fracture electron microscopial visualization and small angle X-ray scattering studies. Br. J. Dermatol. 132, 853-866. doi: 10.1111/j.1365-2133.1995.tb16940.x

Huang, S. M., Kuo, C. H., Chen, C. A., Liu, Y. C., and Shieh, C. J. (2017). RSM and ANN modeling-based optimization approach for the development of ultrasound-assisted liposome encapsulation of piceid. Ultrason. Sonochem. 36, 112-122. doi: 10.1016/j.ultsonch.2016.11.016

Inglut, C. T., Sorrin, A. J., Kuruppu, T., Vig, S., Cicalo, J., Ahmad, H., et al. (2020). Immunological and toxicological considerations for the design of liposomes. Nanomaterials 10:190. doi: 10.3390/nano10020190

Islam Shishir, M. R., Karim, N., Gowd, V., Zheng, X., and Chen, W. (2019). Liposomal delivery of natural product: a promising approach in health research. Trends Food Sci. Technol. 85, 177-200. doi: 10.1016/j.tifs.2019.01.013

Jazz Pharmaceuticals UK (2019). Summary of Product Characteristics. Vyxeos Liposomal $44 \mathrm{mg} / 100 \mathrm{mg}$ Powder for Concentrate for Solution for Infusion, 1-14. Available online at: https://www.medicines.org.uk/emc/product/9442/ smpc/print (accessed April 15, 2020).

Jin, Q., Li, H., Jin, Z., Huang, L., Wang, F., Zhou, Y., et al. (2018). TPGS modified nanoliposomes as an effective ocular delivery system to treat glaucoma. Int. J. Pharm. 553, 21-28. doi: 10.1016/j.ijpharm.2018.10.033 
Joshi, B., and Joshi, A. (2019). "Ultrasound-based drug delivery systems," in Bioelectronics and Medical Devices: From Materials to Devices Fabrication, Applications and Reliability, eds K. Pal, H.-B. Kraatz, A. Khasnobish, S. Bag, and I. Banerjee (Duxford: Elsevier Ltd), 241-260. doi: 10.1016/B978-0-08-102420-1.00014-5

Karim, N., Shishir, M. R. I., and Chen, W. (2020). Surface decoration of neohesperidin-loaded nanoliposome using chitosan and pectin for improving stability and controlled release. Int. J. Biol. Macromol. 164, 2903-2914. doi: 10.1016/j.ijbiomac.2020.08.174

Karimunnisa, S., and Atmaram, P. (2013). Mucoadhesive nanoliposomal formulation for vaginal delivery of an antifungal. Drug Dev. Ind. Pharm. 39, 1328-1337. doi: 10.3109/03639045.2012.707204

Khorasani, S., Danaei, M., and Mozafari, M. R. (2018). Nanoliposome technology for the food and nutraceutical industries. Trends Food Sci. Technol. 79, 106-115. doi: 10.1016/j.tifs.2018.07.009

Khosravi-Darani, K., and Mozafari, M. (2010). Nanoliposome potentials in nanotherapy:a concise overview. Int. J. Nanosci. Nanotechnol. 6, 3-13. Retrieved from http://www.ijnnonline.net/article_3976.html

Kim, A. R., Lee, N. H., Park, Y. M., and Park, S. N. (2019). Preparation and characterization of novel pseudo ceramide liposomes for the transdermal delivery of baicalein. J. Drug Deliv. Sci. Technol. 52, 150-156. doi: 10.1016/j.jddst.2019.04.009

Korting, H. C., Klövekorn, W., and Klövekorn, G. (1997). Comparative efficacy and tolerability of econazole liposomal gel $1 \%$, branded econazole conventional cream $1 \%$ and generic clotrimazole cream $1 \%$ in tinea pedis. Clin. Drug Investig. 14, 286-293. doi: 10.2165/00044011-199714040-00006

Kumar, L., Verma, S., Bhardwaj, A., Vaidya, S., and Vaidya, B. (2014). Eradication of superficial fungal infections by conventional and novel approaches: a comprehensive review. Artif. Cells Nanomed. Biotechnol. 42, 32-46. doi: 10.3109/21691401.2013.769446

Lai, K., Li, Y., Gong, Y., Li, L., Huang, C., Xu, F., et al. (2020). Triptolidenanoliposome-APRPG, a novel sustained-release drug delivery system targeting vascular endothelial cells, enhances the inhibitory effects of triptolide on laser-induced choroidal neovascularization. Biomed. Pharmacother. 131:110737. doi: 10.1016/j.biopha.2020.110737

Lesoin, L., Crampon, C., Boutin, O., and Badens, E. (2011). Preparation of liposomes using the supercritical anti-solvent (SAS) process and comparison with a conventional method. J. Supercrit. Fluids 57, 162-174. doi: 10.1016/j.supflu.2011.01.006

Mahapatro, A., and Singh, D. K. (2011). Biodegradable nanoparticles are excellent vehicle for site directed in-vivo delivery of drugs and vaccines. J. Nanobiotechnol. 9:55. doi: 10.1186/1477-3155-9-55

Mahtab, A., Rabbani, S. A., Neupane, Y. R., Pandey, S., Ahmad, A., Khan, M. A., et al. (2020). Facile functionalization of Teriflunomide-loaded nanoliposomes with Chondroitin sulphate for the treatment of Rheumatoid arthritis. Carbohydr. Polym. 250:116926. doi: 10.1016/j.carbpol.2020.116926

Mahtab, A., Rizwanullah, M., Pandey, S., Leekha, A., Rabbani, S. A., Verma, A. K., et al. (2019). Quality by design driven development and optimization of Teriflunomide loaded Nanoliposomes for treatment of rheumatoid arthritis: an in vitro and in vivo assessments. J. Drug Deliv. Sci. Technol. 51, 383-396. doi: $10.1016 /$ j.jddst.2019.03.008

Malakouti-Nejad, M., Bardania, H., Aliakbari, F., Baradaran-Rafii, A., Elahi, E., Monti, D., et al. (2020). Formulation of nanoliposome-encapsulated bevacizumab (Avastin): statistical optimization for enhanced drug encapsulation and properties evaluation. Int. J. Pharm. 590, 119895. doi: 10.1016/j.ijpharm.2020.119895

Mehdipour, M., Daghigh Kia, H., Nazari, M., and Najafi, A. (2017). Effect of lecithin nanoliposome or soybean lecithin supplemented by pomegranate extract on post-thaw flow cytometric, microscopic and oxidative parameters in ram semen. Cryobiology 78, 34-40. doi: 10.1016/j.cryobiol.2017.07.005

Mehrdad, A., Jamal, H. S., Hamed, H., Parivash, K., Zeinab, G., Didehdar, M., et al. (2016). In vitro evaluation of antifungal effects of nanoliposomal $\mathrm{fl}$ uconazole against $\mathrm{fl}$ uconazole susceptible and resistant Candida species isolated from patients. Biosci. Biotechnol. Res. Commun. 9, 633-642. doi: $10.21786 / \mathrm{bbrc} / 9.4 / 10$

Meure, L. A., Knott, R., Foster, N. R., and Dehghani, F. (2009). The depressurization of an expanded solution into aqueous media for the bulk production of liposomes. Langmuir 25, 326-337. doi: 10.1021/la802511a
Milani, D., Athiyah, U., Hariyadi, D. M., and Pathak, Y. V. (2019). "Surface modification of nanoparticles for targeted drug delivery," in Surface Modification of Nanoparticles for Targeted Drug Delivery, ed P. Yashwant (Totowa, NJ: Humana Press), 207-220. doi: 10.1007/978-3-030-06115-9_11

Mittal, A., Kumar, N., and Chauhan, N. S. (2019). Curcumin encapsulated PEGylated nanoliposomes: a potential anti-infective therapeutic agent. Indian J. Microbiol. 59, 336-343. doi: 10.1007/s12088-019-00811-3

Moghimi, S. M., Hunter, A. C., and Murray, J. C. (2005). Nanomedicine: current status and future prospects. FASEB J. 19, 311-330. doi: 10.1096/fi.04-2747rev

Mohammadabadi, M. R., and Mozafari, M. R. (2018). Enhanced efficacy and bioavailability of thymoquinone using nanoliposomal dosage form. J. Drug Deliv. Sci. Technol. 47, 445-453. doi: 10.1016/j.jddst.2018. 08.019

Mohan, A., Narayanan, S., Balasubramanian, G., Sethuraman, S., and Krishnan, U. M. (2016). Dual drug loaded nanoliposomal chemotherapy: a promising strategy for treatment of head and neck squamous cell carcinoma. Eur. J. Pharm. Biopharm. 99, 73-83. doi: 10.1016/j.ejpb.2015.11.017

Moku, G., Gopalsamuthiram, V. R., Hoye, T. R., and Panyam, J. (2019). "Surface modification of nanoparticles: methods and applications," in Surface Modification of Polymers: Methods and Applications (Weinheim: Wiley-VCH Verlag GmbH \& Co. KGaA), 317-346. doi: 10.1002/9783527819249.ch11

Mont, M. A., Beaver, W. B., Dysart, S. H., Barrington, J. W., and Del Gaizo, D. J. (2018). Local infiltration analgesia with liposomal bupivacaine improves pain scores and reduces opioid use after total knee arthroplasty: results of a randomized controlled trial. J. Arthropl. 33, 90-96. doi: 10.1016/j.arth.2017.07.024

Mordorski, B., Landriscina, A., and Friedman, A. (2016). "An overview of nanomaterials in dermatology," in Nanoscience in Dermatology, eds M. R. Hamblin, P. Avci, and T. W. Prow (London: Elsevier Inc), 31-46. doi: 10.1016/B978-0-12-802926-8.00003-3

Moreno, A. D., Tomás-Pejó, E., Ballesteros, M., and Negro, M. J. (2019). "Pretreatment technologies for lignocellulosic biomass deconstruction within a biorefinery perspective," in Biofuels: Alternative Feedstocks and Conversion Processes for the Production of Liquid and Gaseous Biofuels, eds A. Pandey, C. Larroche, C.-G. Dussap, E. Gnansounou, S. K. Khanal, and S. Ricke (London: Academic Press), 379-399. doi: 10.1016/B978-0-12-816856-1.00016-6

Mortazavi, S. M., Mohammadabadi, M. R., Khosravi-Darani, K., and Mozafari, M. R. (2007). Preparation of liposomal gene therapy vectors by a scalable method without using volatile solvents or detergents. J. Biotechnol. 129, 604-613. doi: 10.1016/j.jbiotec.2007.02.005

Mozafari, M., Reza Reed, C. J., Rostron, C., Kocum, C., and Piskin, E. (2002). Construction of stable anionic liposome-plasmid particles using the heating method: a preliminary investigation. Cell. Mol. Biol. Lett. 7, 923-927.

Mozafari, M. R. (2010). "Chapter 2 - nanoliposomes: preparation and analysis," in Liposomes - Methods and Protocols, Vol. 1: Pharm. Nanocarriers, ed V. Weissig (New York, NY: Humana Press), 41-62.

Mozafari, M. R., and Khosravi-Darani, K. (2007). "An overview of liposomederived nanocarrier technologies," in Nanomaterials and Nanosystems for Biomedical Applications, ed M. R. Mozafari (Dordrecht: Springer Netherlands), 113-123. doi: 10.1007/978-1-4020-6289-6_7

Mozafari, M. R. and Mortazavi, S. M. (2005). Nanoliposomes: From Fundamentals to Recent Developments. Oxford: Trafford Publishing Ltd.

Mozafari, M. R., Reed, C. J., and Rostron, C. (2007). Cytotoxicity evaluation of anionic nanoliposomes and nanolipoplexes prepared by the heating method without employing volatile solvents and detergents. Pharmazie 62, 205-209. doi: $10.1691 /$ ph.2007.3.6045

Mozetič, M. (2019). Surface modification to improve properties of materials. Materials 12:441. doi: 10.3390/ma12030441

Mukherjee, B., Maji, R., Roychowdhury, S., and Ghosh, S. (2016). Toxicological concerns of engineered nanosize drug delivery systems. Am. J. Ther. 23, e139-e150. doi: 10.1097/01.mjt.0000433947.16654.75

Nounou, M., El-Khordagui, L., Khalafallah, N., and Khalil, S. (2008). Liposomal formulation for dermal and transdermal drug delivery: past, present and future. Recent Pat. Drug Deliv. Formul. 2, 9-18. doi: 10.2174/187221108783331375

Papachristodoulou, A., Signorell, R. D., Werner, B., Brambilla, D., Luciani, P., Cavusoglu, M., et al. (2019). Chemotherapy sensitization of glioblastoma by focused ultrasound-mediated delivery of therapeutic liposomes. J. Controlled Release 295, 130-139. doi: 10.1016/j.jconrel.2018.12.009 
Patil, Y. P., and Jadhav, S. (2014). Novel methods for liposome preparation. Chem. Phys. Lipids 177, 8-18. doi: 10.1016/j.chemphyslip.2013.10.011

Perez, A. P., Altube, M. J., Schilrreff, P., Apezteguia, G., Celes, F. S., Zacchino, S., et al. (2016). Topical amphotericin B in ultradeformable liposomes: formulation, skin penetration study, antifungal and antileishmanial activity in vitro. Colloids Surfaces B 139, 190-198. doi: 10.1016/j.colsurfb.2015.12.003

Permana, A. D., Tekko, I. A., McCrudden, M. T. C., Anjani, Q. K., Ramadon, D., McCarthy, H. O., et al. (2019). Solid lipid nanoparticle-based dissolving microneedles: a promising intradermal lymph targeting drug delivery system with potential for enhanced treatment of lymphatic filariasis. J. Controlled Release 316, 34-52. doi: 10.1016/j.jconrel.2019.10.004

Phan, H. T., and Haes, A. J. (2019). What Does Nanoparticle Stability Mean? J. Phys. Chem. C 123, 16495-16507. doi: 10.1021/acs.jpcc.9b00913

Psimadas, D., Georgoulias, P., Valotassiou, V., and Loudos, G. (2012). Molecular nanomedicine towards cancer. J. Pharm. Sci. 101, 2271-2280. doi: 10.1002/jps.23146

Rahimpour, Y., and Hamishehkar, H. (2012). Liposomes in cosmeceutics. Expert Opin. Drug Deliv. 9, 443-455. doi: 10.1517/17425247.2012.666968

Rasti, B., Jinap, S., Mozafari, M. R., and Yazid, A. M. (2012). Comparative study of the oxidative and physical stability of liposomal and nanoliposomal polyunsaturated fatty acids prepared with conventional and Mozafari methods. Food Chem. 135, 2761-2770. doi: 10.1016/j.foodchem.2012.07.016

Risaliti, L., Pini, G., Ascrizzi, R., Donato, R., Sacco, C., Bergonzi, C., et al. (2020). Artemisia annua essential oil extraction, characterization, and incorporation in nanoliposomes, smart drug delivery systems against Candida species. J. Drug Deliv. Sci. Technol. 59:101849. doi: 10.1016/j.jddst.2020.101849

Rizvi, S. A. A., and Saleh, A. M. (2018). Applications of nanoparticle systems in drug delivery technology. Saudi Pharm. J.26, 64-70. doi: $10.1016 /$ j.jsps.2017.10.012

Rudra, A., Deepa, R. M., Ghosh, M. K., Ghosh, S., and Mukherjee, B. (2010). Doxorubicin-loaded phosphatidylethanolamine-conjugated nanoliposomes: in vitro characterization and their accumulation in liver, kidneys, and lungs in rats. Int. J. Nanomed. 5:811. doi: 10.2147/IJN.S13031

Rushmi, Z. T., Akter, N., Mow, R. J., Afroz, M., Kazi, M., de Matas, M., et al. (2017). The impact of formulation attributes and process parameters on black seed oil loaded liposomes and their performance in animal models of analgesia. Saudi Pharm. J. 25, 404-412. doi: 10.1016/j.jsps.2016.09.011

Saadat, E., Dinarvand, R., and Ebrahimnejad, P. (2016). Encapsulation of nystatin in nanoliposomal formulation: characterization, stability study and antifungal activity against Candida albicans. Pharm. Biomed. Res. 2, 44-54. doi: 10.18869/acadpub.pbr.2.1.44

Saji, V. S., Choe, H. C., and Yeung, K. W. K. (2010). Nanotechnology in biomedical applications: a review. Int. J. Nano Biomater. 3, 119-139. doi: 10.1504/IJNBM.2010.037801

Saka, R., Jain, H., Kommineni, N., Chella, N., and Khan, W. (2020). Enhanced penetration and improved therapeutic efficacy of bexarotene via topical liposomal gel in imiquimod induced psoriatic plaque model in BALB/c mice. J. Drug Deliv. Sci. Technol. 58:101691. doi: 10.1016/j.jddst.2020.101691

Sakdiset, P., Okada, A., Todo, H., and Sugibayashi, K. (2018). Selection of phospholipids to design liposome preparations with high skin penetration-enhancing effects. J. Drug Deliv. Sci. Technol. 44, 58-64. doi: 10.1016/j.jddst.2017.11.021

Salem, H. F., Ahmed, S. M., and Omar, M. M. (2016). Liposomal flucytosine capped with gold nanoparticle formulations for improved ocular delivery. Drug Des. Devel. Ther. 10:277. doi: 10.2147/DDDT.S91730

Samadi, N., Aberoomand Azar, P., Waqif Husain, S., Maibach, H. I., and Nafisi, S. (2020). Experimental design in formulation optimization of vitamin K1 oxide-loaded nanoliposomes for skin delivery. Int. J. Pharm. 579:119136. doi: 10.1016/j.ijpharm.2020.119136

Sarrafha, M. R., Hashemi, S. J., Rezaei, S., and Bayat, M. (2018). In vitro evaluation of the effects of fluconazole and nano-fluconazole on aspergillus flavus and A. Fumigatus isolates. Jundishapur J. Microbiol. 11:e57875. doi: 10.5812/jjm.57875

Sawicki, K., Czajka, M., Matysiak-Kucharek, M., Fal, B., Drop, B., MęczyńskaWielgosz, S., et al. (2019). Toxicity of metallic nanoparticles in the central nervous system. Nanotechnol. Rev. 8, 175-200. doi: 10.1515/ntrev-2019-0017

Schwartz, S., Kontoyiannis, D. P., Harrison, T., and Ruhnke, M. (2018). Advances in the diagnosis and treatment of fungal infections of the CNS. Lancet Neurol. 17, 362-372. doi: 10.1016/S1474-4422(18)30030-9
Shah, S. P., and Misra, A. (2004). Development of liposomal Amphotericin B dry powder inhaler formulation. Drug Deliv. 11, 247-253. doi: 10.1080/10717540490467375

Shakeel, K., Raisuddin, S., Ali, S., Imam, S. S., Rahman, M. A., Jain, G. K., et al. (2019). Development and in vitro/in vivo evaluation of artemether and lumefantrine co-loaded nanoliposomes for parenteral delivery. J. Liposome Res. 29, 35-43. doi: 10.1080/08982104.2017.1410173

Shalaby, T. I., El-Refaie, W. M., Shams El-Din, R. S., and Hassanein, S. A. (2020). Smart ultrasound-triggered doxorubicin-loaded nanoliposomes with improved therapeutic response: a comparative study. J. Pharm. Sci. 109, 2567-2576. doi: 10.1016/j.xphs.2020.05.008

Sharma, A., Madhunapantula, S. V., and Robertson, G. P. (2012). Toxicological considerations when creating nanoparticle-based drugs and drug delivery systems. Expert Opin. Drug Metab. Toxicol. 8, 47-69. doi: $10.1517 / 17425255.2012 .637916$

Shi, N.-Q., and Qi, X.-R. (2018). "Preparation of drug liposomes by reversephase evaporation," in Liposome-Based Drug Delivery Systems, eds W.-L. Lu and X.-R. Qi (Berlin; Heidelberg: Springer), 1-10. doi: 10.1007/978-3-662-492 31-4_3-1

Siepmann, J., Siegel, R. A., and Rathbone, M. J. (2012). Fundamentals and Applications of Controlled Release Drug Delivery. (Boston, MA: Springer). doi: 10.1007/978-1-4614-0881-9

Singh, N., Joshi, A., Toor, A. P., and Verma, G. (2017). "Drug delivery: advancements and challenges," in Nanostructures for Drug Delivery, eds E. Andronescu and A. M. Grumezescu (Amsterdam: Elsevier Inc), 865-886. doi: 10.1016/B978-0-323-46143-6.00027-0

Sperling, R. A., and Parak, W. J. (2010). Surface modification, functionalization and bioconjugation of colloidal Inorganic nanoparticles. Philos. Trans. R. Soc. A Math. Phys. Eng. Sci. 368, 1333-1383. doi: 10.1098/rsta.2009.0273

$\mathrm{Su}, \mathrm{C}$., Liu, Y., He, Y., and Gu, J. (2018). Analytical methods for investigating in vivo fate of nanoliposomes: a review. J. Pharm. Anal. 8, 219-225. doi: 10.1016/j.jpha.2018.07.002

Subramani, T., and Ganapathyswamy, H. (2020). An overview of liposomal nanoencapsulation techniques and its applications in food and nutraceutical. J. Food Sci. Technol. 57, 3545-3555. doi: 10.1007/s13197-020-04360-2

Taboada, J., and Grooters, A. M. (2008). "Chapter 9 - Systemic antifungal therapy," in Small Animal Clinical Pharmacology, 2nd Edn, eds J. E. Maddison, D. B. Church, and S. W. Page (Philadelphia, PA: Elsevier Ltd), 186-197. doi: 10.1016/B978-070202858-8.50011-7

Taira, M. C., Chiaramoni, N. S., Pecuch, K. M., and Alonso-Romanowski, S. (2004). Stability of liposomal formulations in physiological conditions for oral drug delivery. Drug Deliv. 11, 123-128. doi: 10.1080/10717540490280769

Tekade, R. K., Maheshwari, R., Soni, N., Tekade, M., and Chougule, M. B. (2017). "Nanotechnology for the development of nanomedicine," in NanotechnologyBased Approaches for Targeting and Delivery of Drugs and Genes, eds V. Mishra, P. Kesharwani, M. C. Iqbal Mohd Amin, and A. Iyer (London: Elsevier Inc), 3-61. doi: 10.1016/B978-0-12-809717-5.00001-4

Thian, E. S., Huang, J., Aizawa, M., Lim, P. N., Huang, J., Aizawa, M., et al. (2017). "Overview of Nanobioceramics," in Nanobioceramics for Healthcare Applications, eds E. S. Thian, H. Jie, and A. Mamoru (Singapore), 1-22. doi: 10.1142/9781786341341_0001

Toniazzo, T., Peres, M. S., Ramos, A. P., and Pinho, S. C. (2017). Encapsulation of quercetin in liposomes by ethanol injection and physicochemical characterization of dispersions and lyophilized vesicles. Food Biosci. 19, 17-25. doi: 10.1016/j.fbio.2017.05.003

Touti, R., Noun, M., Guimberteau, F., Lecomte, S., and Faure, C. (2020) What is the fate of multi-lamellar liposomes of controlled size, charge and elasticity in artificial and animal skin? Eur. J. Pharm. Biopharm. 151, 18-31. doi: 10.1016/j.ejpb.2020.03.017

Trucillo, P., Campardelli, R., Scognamiglio, M., and Reverchon, E. (2019). Control of liposomes diameter at micrometric and nanometric level using a supercritical assisted technique. J. CO2 Util. 32, 119-127. doi: 10.1016/j.jcou.2019.04.014

Trucillo, P., Ferrari, P. F., Campardelli, R., Reverchon, E., and Perego, P. (2020). A supercritical assisted process for the production of amoxicillin loaded liposomes for anti-microbial applications. J. Supercrit. Fluids 163:104842. doi: 10.1016/j.supflu.2020.104842

Tuerdi, N., Anwaier, G., Zhang, X., Liu, S., Shen, W., Liu, W., et al. (2020). Simvastatin nanoliposome induces myocardial and hepatic toxicities due 
to its absorption enhancement in mice. Asian J. Pharm. Sci. 15, 112-120. doi: 10.1016/j.ajps.2019.02.002

Tuerdi, N., Xu, L., Zhu, B., Chen, C., Cao, Y., Wang, Y., et al. (2016). Preventive effects of simvastatin nanoliposome on isoproterenolinduced cardiac remodeling in mice. Nanomedicine 12, 1899-1907. doi: 10.1016/j.nano.2016.05.002

Van Tran, V., Loi Nguyen, T., Moon, J. Y., and Lee, Y. C. (2019). Core-shell materials, lipid particles and nanoemulsions, for delivery of active anti-oxidants in cosmetics applications: challenges and development strategies. Chem. Eng. J. 368, 88-114. doi: 10.1016/j.cej.2019.02.168

Vanitha, G., Rajavel, K., Boopathy, G., Veeravazhuthi, V., and Neelamegam, P. (2017). Physiochemical charge stabilization of silver nanoparticles and its antibacterial applications. Chem. Phys. Lett. 669, 71-79. doi: 10.1016/j.cplett.2016.11.037

Varona, S., Martín, Á., and Cocero, M. J. (2011). Liposomal incorporation of lavandin essential oil by a thin-film hydration method and by particles from gas-saturated solutions. Indus. Eng. Chem. Res. 50, 2088-2097. doi: $10.1021 /$ ie102016r

Veloso, D. F. M. C., Benedetti, N. I. G. M., Avila, R. I., Bastos, T. S. A., Silva, T. C., Silva, M. R. R., et al. (2018). Intravenous delivery of a liposomal formulation of voriconazole improves drug pharmacokinetics, tissue distribution, and enhances antifungal activity. Drug Deliv. 25, 1585-1594. doi: 10.1080/10717544.2018.1492046

Wang, W., Lu, K. J., Yu, C. H., Huang, Q. L., and Du, Y. Z. (2019). Nano-drug delivery systems in wound treatment and skin regeneration. J. Nanobiotechnol. 17, 1-15. doi: 10.1186/s12951-019-0514-y

Wang, Y., and Kohane, D. S. (2017). External triggering and triggered targeting strategies for drug delivery. Nat. Rev. Mater. 2:17020. doi: 10.1038/natrevmats.2017.20

Xu, L., Liang, H. W., Yang, Y., and Yu, S. H. (2018). Stability and reactivity: positive and negative aspects for nanoparticle processing. Chem. Rev. 118, 3209-3250. doi: 10.1021/acs.chemrev.7b00208

Yang, B., Jiang, J., Jiang, L., Zheng, P., Wang, F., Zhou, Y., et al. (2020). Chitosan mediated solid lipid nanoparticles for enhanced liver delivery of zedoary turmeric oil in vivo. Int. J. Biol. Macromol. 149, 108-115. doi: 10.1016/j.ijbiomac.2020.01.222

Yang, J., Wen, C., Pan, C., Guo, H., Zhao, W., Zhang, J., et al. (2019). Nanoliposomal multi-drug delivery system with reduced toxicity and multidrug resistance. J. Mater. Sci. 54, 9718-9728. doi: 10.1007/s10853-019-03573-x

Ye, H., Zhou, L., Jin, H., Chen, Y., Cheng, D., and Jiang, Y. (2020). Sorafenibloaded long-circulating nanoliposomes for liver cancer therapy. BioMed Res. Int. 2020:1351046. doi: 10.1155/2020/1351046

Yingyuad, P., Sinthuvanich, C., Leepasert, T., Thongyoo, P., and Boonrungsiman, S. (2018). Preparation, characterization and in vitro evaluation of calothrixin B liposomes. J. Drug Deliv. Sci. Technol. 44, 491-497. doi: 10.1016/j.jddst.2018.02.010

Zamani, P., Momtazi-Borojeni, A. A., Nik, M. E., Oskuee, R. K., and Sahebkar, A. (2018). Nanoliposomes as the adjuvant delivery systems in cancer immunotherapy. J. Cell. Physiol. 233, 5189-5199. doi: 10.1002/jcp.26361

Zandi, G., Lotfipour, F., Ghanbarzadeh, S., Medghalchi, M., and Hamishehkar, H. (2018). A comparative study on the potentials of nanoliposomes and nanoethosomes for Fluconazole delivery. J. Drug Deliv. Sci. Technol. 44, 264-269. doi: 10.1016/j.jddst.2018.01.003

Zhai, H., and Maibach, H. I. (2002). Occlusion vs. skin barrier function. Skin Res. Technol. 8, 1-6. doi: 10.1046/j.0909-752x.2001.10311.x

Zhang, H. (2016). Onivyde for the therapy of multiple solid tumors. Onco Targets Ther. 9, 3001-3007. doi: 10.2147/OTT.S105587

Zhang, Q., Ou, C., Ye, S., Song, X., and Luo, S. (2017). Construction of nanoscale liposomes loaded with melatonin via supercritical fluid technology. J. Microencapsul. 34, 687-698. doi: 10.1080/02652048.2017.1376001

Zhang, W., Sun, Y., Li, Y., Shen, R., Ni, H., and Hu, D. (2012). Preparation and influencing factors of sirolimus liposome by supercritical fluid. Artif. Cells Blood Substitutes Biotechnol. 40, 62-65. doi: 10.3109/10731199.2011.585618

Zhao, L., and Temelli, F. (2015). Preparation of liposomes using supercritical carbon dioxide via depressurization of the supercritical phase. J. Food Eng. 158, 104-112. doi: 10.1016/j.jfoodeng.2015.03.004

Zucker, D., Andriyanov, A. V., Steiner, A., Raviv, U., and Barenholz, Y. (2012). Characterization of PEGylated nanoliposomes co-remotely loaded with topotecan and vincristine: relating structure and pharmacokinetics to therapeutic efficacy. J. Controlled Release 160, 281-289. doi: 10.1016/j.jconrel.2011.10.003

Zucker, D., Marcus, D., Barenholz, Y., and Goldblum, A. (2009). Liposome drugs' loading efficiency: a working model based on loading conditions and drug's physicochemical properties. J. Controlled Release 139, 73-80. doi: 10.1016/j.jconrel.2009. 05.036

Conflict of Interest: The authors declare that the research was conducted in the absence of any commercial or financial relationships that could be construed as a potential conflict of interest.

Copyright (c) 2020 Aguilar-Pérez, Avilés-Castrillo, Medina, Parra-Saldivar and Iqbal. This is an open-access article distributed under the terms of the Creative Commons Attribution License (CC BY). The use, distribution or reproduction in other forums is permitted, provided the original author(s) and the copyright owner(s) are credited and that the original publication in this journal is cited, in accordance with accepted academic practice. No use, distribution or reproduction is permitted which does not comply with these terms. 